\title{
The Real Effects of Modern Information Technologies*
}

\author{
Itay Goldstein $^{\mathrm{a}}$, Shijie Yang ${ }^{\mathrm{b}}$, Luo Zuo $^{\mathrm{c}}$ \\ ${ }^{a}$ Wharton School, University of Pennsylvania \\ ${ }^{\mathrm{b}}$ School of Management and Economics, Chinese University of Hong Kong, Shenzhen \\ ${ }^{c}$ Samuel Curtis Johnson Graduate School of Management, Cornell University
}

December 2020

\begin{abstract}
Using the staggered implementation of the EDGAR system from 1993 to 1996 as a shock to information dissemination technologies, we examine the potential benefits and costs of modern information technologies on the real economy. On the one hand, we document results confirming the conventional wisdom that broader information dissemination leads to an increase in the level of equity financing and corporate investment. On the other hand, we provide evidence that greater dissemination of corporate disclosures crowds out private information acquisition and reduces managerial learning from stock prices. This crowdingout effect, while often overlooked, is particularly pronounced in high-growth firms. Our findings suggest that it is important to consider this tradeoff between improved equity financing and reduced managerial learning when evaluating the economic effects of modern information technologies. Our evidence suggests that the former effect dominates in value firms while the latter effect dominates in high-growth firms.
\end{abstract}

Keywords: Corporate Investment, Information Technologies, EDGAR, Equity Financing, Managerial Learning.

JEL Classification: G12, G14, G31, M41.

\footnotetext{
${ }^{*}$ We gratefully acknowledge helpful comments from John Core, Andrew Leone, Chen Lin, K. Ramesh, Sugata Roychowdhury, Eric So, Sri Sridhar, Rodrigo Verdi, and Joseph Weber, as well as seminar participants at Cornell University, the Massachusetts Institute of Technology, Northwestern University, Wuhan University, and the 2020 Virtual Conference of Accounting Society of China.
} 


\section{Introduction}

A fundamental question in financial economics is whether and how information disclosure in financial markets affects the real economy (Goldstein and Yang 2017). To understand this question, a large literature in accounting and finance has developed to examine the effects of financial reporting and disclosure on corporate investment (Roychowdhury, Shroff, and Verdi 2019). Prior research on the real effects of corporate disclosures often assumes that accounting information, once disclosed by a firm, is costlessly disseminated and equally available to the investing public. However, a different line of research shows that the costs of monitoring for, acquiring, and analyzing firm disclosures can be substantial (Lee and So 2015; Blankespoor, deHaan, and Marinovic 2020). In this paper, we examine whether and how investors' costs of accessing firm disclosures affect corporate investment by exploiting the emergence of modern information technologies that reduce these costs.

Modern information technologies have greatly facilitated timely dissemination of information to a broad base of investors at low costs (Gao and Huang 2020). With technological advances, the U.S. Securities and Exchange Commission (SEC) has implemented a series of regulatory changes to improve the public's accessibility of firm disclosures. For example, in 1993 the SEC began to mandate electronic submission of corporate filings through the Electronic Data Gathering, Analysis, and Retrieval (EDGAR) system, and in 2013 the SEC allowed companies to use social media outlets (e.g., Facebook and Twitter) to announce key information. The rationale of these regulatory reforms often follows the conventional wisdom: greater and broader information dissemination can lead to an increase in the amount of total information in the marketplace, which improves the functioning of the financial market and firms' access to external 
capital, thereby allowing firms to tap into new investment opportunities (e.g., Bernanke and Gertler 1989; Kiyotaki and Moore 1997).

While intuitive, this line of reasoning is incomplete because it misses an important feature of real-world financial markets: most trading occurs in secondary markets where securities are traded among investors without capital flowing to firms. Bond, Edmans, and Goldstein (2012) note that secondary market prices can significantly affect the real economy because these prices convey useful information to corporate managers. Hence, to evaluate the economic effects of modern information technologies on firms, we need to consider how these technologies affect not only the extent to which prices reflect all available information (i.e., forecasting price efficiency) but also the extent to which prices reveal new information to managers (i.e., revelatory price efficiency). These two types of price efficiency are often different from each other, and the latter is manifested in managerial actions. In this paper, we investigate the potential benefits and costs of modern information technologies on firms by considering both types of price efficiency. Importantly, we assess whether and when the benefits exceed the costs and vice versa.

Traditional models predict that a decline in information acquisition costs leads to an increase in forecasting price efficiency (Verrecchia 1982; Diamond 1985). Gao and Huang (2020) provide evidence supporting this prediction. Thus, the benefits of modern information technologies are relatively straightforward. However, we argue that modern information technologies can also entail costs on firms (besides the initial implementation costs). Under the managerial learning perspective, whether information technologies enhance or impede real efficiency depends on its net effect on revelatory price efficiency, which can move in an opposite direction from forecasting price efficiency (Bond, Edmans, and Goldstein 2012). The notion of revelatory price efficiency 
builds on the idea that prices are a useful source of information (Hayek 1945). ${ }^{1}$ Stock prices can reveal traders' private information that is otherwise not available to managers (Grossman and Stiglitz 1980; Glosten and Milgrom 1985; Kyle 1985; Easley and O’Hara 1987), and hence can affect managers' forecasts about their own firms' fundamentals (Zuo 2016; Jayaraman and Wu 2020) and their investment decisions (Dye and Sridhar 2002; Luo 2005; Chen, Goldstein, and Jiang 2007)..$^{2}$

By definition, the extent of revelatory price efficiency is manifested in changes in managerial behavior. ${ }^{3}$ There is no direct measure of revelatory price efficiency, and prior research largely relies on the investment-to-price sensitivity framework to draw inferences on managerial learning (e.g., Chen, Goldstein, and Jiang 2007; Bakke and Whited 2010; Foucault and Frésard 2012, 2014; Bai, Philippon, and Savov 2016; Edmans, Jayaraman, and Schneemeier 2017; Dessaint, Foucault, Frésard, and Matray 2019; Jayaraman and Wu 2019; Lin, Liu, and Sun 2019). The intuition is that the sensitivity of investment to price will be stronger when movements in the price are more likely to originate from information that is new to the manager than from information that was already known to her. We develop a stylized model in Section 4 to illustrate the basic mechanism underlying this general prediction.

\footnotetext{
${ }^{1}$ Fama and Miller (1972, p. 335) note: “(An efficient market) has a very desirable feature. In particular, at any point in time market prices of securities provide accurate signals for resource allocation; that is, firms can make productioninvestment decisions ..." Rappaport (1987) further note: "(Managers) can learn a lot if they analyze what the stock price tells them about the market's expectations for their company's performance." George Soros (a prominent trader) calls this feature "reflexivity" and state: "Stock prices are not merely passive reflections; they are active ingredients in the process in which both stock prices and the fortunes of companies whose stocks are traded are determined" (Soros 1994, p. 49).

${ }^{2}$ As a recent anecdote of managerial learning from the market, Intercontinental Exchange (ICE, the parent company of the New York Stock Exchange) quickly abandoned its pursuit of eBay after the news of its interest in a deal triggered a $10.5 \%$ drop in its stock price. See "NYSE Owner Abandons Potential eBay Deal" by the Wall Street Journal (February 6, 2020).

${ }^{3}$ While revelatory price efficiency is necessary for managerial learning, it is not sufficient. The extent to which managers incorporate price information in their decision making depends on their willingness and ability to learn, which is ultimately an empirical question.
} 
Theories predict two opposite effects of modern information technologies on revelatory price efficiency and managerial learning. On the one hand, greater and broader dissemination of corporate disclosures naturally leads to more aggressive trading on this information, which can reduce uncertainty in trading on other fundamental information and encourage more acquisition and trading of information potentially unknown to managers, resulting in a crowding-in effect (Goldstein and Yang 2015). On the other hand, a decline in the cost of accessing corporate disclosures can reduce the equilibrium demand for more precise fundamental signals obtained with a deeper analysis (Dugast and Foucault 2018). This crowding-out effect happens because it takes time to develop high precision signals and the trading profits based on these signals are reduced when low precision signals have already been reflected in prices. Given these theoretical tensions, how modern information technologies affect managerial learning and real efficiency is therefore an empirical question.

To evaluate the benefits and costs of modern information technologies, we exploit the staggered implementation of the EDGAR system from 1993 to 1996 as a shock to information dissemination technologies that alter the timeliness and costs of accessing firm disclosures (Gao and Huang 2020; Chang, Ljungqvist, and Tseng 2020). On February 23, 1993, the SEC specified a phase-in schedule for registered firms to start filing on EDGAR in ten discrete groups (SEC Release No. 33-6977). Firms in the first and last groups became EDGAR filers in April 1993 and May 1996, respectively. This staggered mandatory implementation of the EDGAR system reduces potential endogeneity concerns caused by unobserved firm-, industry-, or market-level shocks or reverse causality (Leuz and Wysocki 2016). For an omitted variable to confound our findings, it needs to affect different groups of firms at discrete points in time as specified in the phase-in schedule. 
Using a staggered difference-in-differences (diff-in-diff) research design, we find that the EDGAR implementation leads to a $10 \%$ increase in the level of corporate investment but a $20 \%$ decrease in the investment-to-price sensitivity. A standard dynamic test shows no difference in pre-trends in investment behavior between the treatment and control groups, supporting the parallel-trends assumption. The observed increase in the level of corporate investment follows the conventional wisdom: EDGAR inclusion improves firms' information environments, access to equity capital, and their ability to undertake investment projects. Using a path analysis design (e.g., Landsman, Maydew, and Thornock 2012), we provide evidence supporting this equity financing channel.

The observed decrease in the investment-to-price sensitivity suggests reduced managerial learning from the market after EDGAR inclusion. ${ }^{4}$ We argue that this reduction in learning happens because greater dissemination of corporate disclosures levels the playing field, discourages private information acquisition, and crowds out some information that is new to managers. While there is no direct measure of revelatory price efficiency, we conduct three sets of analyses to support the managerial learning channel. First, we show that, after a firm becomes an EDGAR filer, it experiences a decrease in ownership by institutional investors, especially those who are more likely to actively acquire and trade on information. This result suggests that the EDGAR implementation provides greater benefits to less-sophisticated retail investors and discourages private information acquisition by more-sophisticated institutional investors.

Second, we use two measures based on structural market microstructure models to assess the equilibrium level of private information in prices. The first measure is the probability of

\footnotetext{
${ }^{4}$ Greater financing and stronger governance after the EDAGR implementation can lead to an increase in the investment-to-price sensitivity. Thus, the observed decrease in the investment-to-price sensitivity is unlikely to be driven by these alternative channels.
} 
informed trading based on the Generalized PIN model recently developed in Duarte, $\mathrm{Hu}$, and Young (2020), and the second measure is the adverse selection component of the bid-ask spread (Madhavan, Richardson, and Roomans 1997; Armstrong, Core, Taylor, and Verrecchia 2011). These two measures are complementary as the former relies on order flows to identify private information arrival while the latter directly measures the extent to which prices are affected by unexpected order flows. We show that the EDGAR implementation leads to a decrease in both measures of private information.

Third, we explore cross-sectional differences between firms to provide a tighter link between investors' private information and managerial learning. The condition for managerial learning is that investors collectively possess some information that managers do not have. Learning models commonly assume that investors' information advantage lies in evaluating growth options, which requires analyzing market trends, industry competition, and consumer demand, as well as making comparisons with other firms; investors are unlikely to possess new information about a firm's assets in place since managers are the ones who put those assets there (e.g., Gao and Liang 2013; Bai, Philippon, and Savov 2016; Edmans, Jayaraman, and Schneemeier 2017; Goldstein and Yang 2019). ${ }^{5}$ Thus, the EDGAR implementation is likely to reduce managerial learning to a greater extent in growth firms than in value firms. Consistent with this cross-sectional prediction, we find that growth firms experience a greater reduction in institutional ownership, privately informed trading, and the investment-to-price sensitivity after the EDGAR shock than value firms.

As a final step, we examine the overall effect of the EDGAR implementation on ex post firm performance. On the one hand, greater dissemination of corporate disclosures and improved

\footnotetext{
${ }^{5}$ The argument is not that the manager is less informed than investors, but only that the manager does not have perfect information about every decision-relevant factor that is related to the firm's growth opportunities.
} 
stock market liquidity can better incentivize managers (who are the agents of the shareholders) to take value-maximizing actions. On the other hand, reduced managerial learning, especially in growth firms, can hurt firm performance (despite managers' best intentions). Empirically, we find that, on average, the EDGAR implementation leads to an increase in firm profitability and sales growth in value firms but hurts performance in high-growth firms where managerial learning from the market is particularly important.

It is worth noting that increased timeliness and reduced costs of accessing firm disclosures might alter managers' reporting incentives (by enhancing investor monitoring and/or increasing capital market pressure) and affect firms' disclosure quality. Thus, we do not claim that the EDGAR implementation represents a clean shock to information dissemination while holding constant the information being disclosed. This possibility adds nuance to the interpretation of our results but does not change our inferences that the documented real effects of the EDGAR shock are due to a reduction in investors' costs of accessing corporate filings.

The remainder of the paper is organized as follows. Section 2 reviews related literature and discusses our paper's contributions. Section 3 lays out the institutional setting and describes our sample and empirical specification. Section 4 develops a stylized model that illustrates the theoretical underpinnings of the investment-to-price sensitivity framework. Section 5 presents the main analysis on corporate investment. Section 6 delves into the underlying mechanisms that explain the main results. Section 7 provides some additional analyses. Section 8 concludes and discusses some directions for future research.

\section{Related Literature}

Modern information technologies have fundamentally changed the way that the investing public monitors for, acquires, and analyzes firm disclosures. A natural question that arises is 
whether and how these technologies affect capital markets and firms. Gao and Huang (2020) first exploit the staggered timing of the EDGAR implementation and provide plausibly causal evidence that EDGAR inclusion leads to an increase in information production by individual investors and sell-side analysts, and a higher stock pricing efficiency. ${ }^{6}$ Their results are based on the amount of total information in individual trades, analyst forecasts, and prices, and suggest that the EDGAR implementation improves forecasting price efficiency. We follow the empirical methodology of Gao and Huang (2020), highlight the opposite effects of EDGAR inclusion on the two types of price efficiency (i.e., forecasting price efficiency versus revelatory price efficiency), and demonstrate the dual effects of modern information technologies on the real economy.

Specifically, our results show that broader information dissemination leads to an increase in stock liquidity, a decrease in return volatility, and an increase in the level of equity financing and corporate investment. These outcomes directly follow Gao and Huang (2020) and are consistent with the conventional wisdom that guides regulators in promoting broader and more timely information dissemination. More importantly, we argue and find that this analysis is incomplete as greater dissemination of corporate disclosures crowds out private information acquisition and reduces managerial learning from prices. This crowding-out effect, while often overlooked, is particularly pronounced in high-growth firms. Our findings provide evidence that investors' costs of accessing firm disclosures have different implications for forecasting price efficiency and revelatory price efficiency, both of which significantly affect the real economy.

As evidence of the importance of this line of research, several concurrent studies also exploit the staggered timing of the EDGAR implementation and examine different outcome

\footnotetext{
${ }^{6}$ Earlier studies treat the implementation of the EDGAR system as a one-time shock (e.g., Asthana, Balsam, and Sankaraguruswamy 2004). Griffin (2003) and Li and Ramesh (2009) document significant stock price reactions surrounding $10-\mathrm{K}$ and $10-\mathrm{Q}$ filings in the EDGAR era.
} 
variables, including analyst forecasts (Chang, Ljungqvist, and Tseng 2020), investor disagreement (Chang, Hsiao, Ljungqvist, and Tseng 2020), information asymmetry (Gomez 2020), earnings management (Liu 2019), and stock price crash risk (Guo, Lisic, Stuart, and Wang 2019). In contrast to our work, these studies do not consider the notion of revelatory price efficiency since their focus is not on how EDGAR affects the real economy. More related to our work are three studies that also examine the real effects of EDGAR: Li and Qi (2020) and Lai, Lin, and Ma (2020) focus on the benefits of EDGAR and show that EDGAR inclusion leads to lower information asymmetry, lower cost of equity capital, and higher capital investment. Bird, Karolyi, Ruchti, and Truong (2020) focus on the costs of EDGAR and show that EDGAR inclusion leads to a lower investmentto-price sensitivity. Compared with these concurrent studies, our paper provides a more comprehensive picture of the relations at play by considering both types of price efficiency and by assessing whether and when the benefits exceed the costs and vice versa. Our findings highlight that it is important to consider the tradeoff between improved equity financing and reduced managerial learning when evaluating the economic effects of modern information technologies. Our evidence suggests that the former effect dominates in value firms while the latter effect dominates in high-growth firms.

Our paper makes contributions to three strands of literature. ${ }^{7}$ First, it contributes to the literature on the effects of financial reporting and disclosure on corporate investment (see reviews in Kanodia and Sapra (2016), Leuz and Wysocki (2016), and Roychowdhury, Shroff, and Verdi (2019)). Prior research in this literature often assumes that investors' costs of acquiring and analyzing corporate disclosures are negligible and focuses on whether and how disclosure content, quantity, quality, or timing affects managerial actions. Our findings highlight the importance of

\footnotetext{
${ }^{7}$ Several concurrent studies also touch some of the issues we examine but our study is much more comprehensive as discussed above.
} 
considering information dissemination beyond information production when examining the real effects of corporate disclosures.

Second, our paper contributes to the literature assessing how the costs of monitoring for, acquiring, and analyzing corporate disclosures affect investor information choices, trades, and market outcomes (see reviews in Lee and So (2015), Kothari, So, and Verdi (2016), and Blankespoor, deHaan, and Marinovic (2020)). Prior research in this area often focuses on how disclosure processing costs affect the amount of total information in individual trades, analyst forecasts, or prices (i.e., forecasting price efficiency). We develop a stylized model based on the investment-to-price sensitivity framework and provide evidence suggesting that the EDGAR implementation decreases the amount of information in prices that is new to managers (i.e., revelatory price efficiency) despite its positive effect on forecasting price efficiency.

Third, our paper extends the literature on the real effects of the financial markets (see reviews in Bond, Edmans, and Goldstein (2012) and Goldstein and Yang (2017)). Most related to our work is Jayaraman and Wu (2019) who find a reduction in a firm's investment-to-price sensitivity after the firm increases segment disclosures. Their results present evidence of reduced managerial learning after an increase in the level of disclosures. A fundamental difference between their work and ours is that they abstract away from investors' costs of accessing disclosures. In contrast, we provide direct evidence on the implications of these costs on corporate investment decisions.

\section{Institutional Setting, Sample, and Empirical Specification}

\subsection{Institutional Setting}

Before the implementation of the EDGAR system in 1993, SEC-registered firms were required to submit multiple paper copies of filings to the SEC. These paper copies of filings were 
stored in the SEC's public reference rooms located in three locations (i.e., Washington D.C., New York, and Chicago), and typically one or two paper copies of the same filing were available for access in each location. As vividly noted in a New York Times (1982) article, "[t]he place can be a zoo" and "files are often misplaced or even stolen." "To view these corporate filings, investors could either physically visit one of the reference rooms or subscribe to commercial data vendors for a nontrivial fee. ${ }^{9}$ Data aggregators such as Standard \& Poor's were only able to disseminate SEC filings to its commercial customers with a significant production lag (D'Souza, Ramesh, and Shen 2010). ${ }^{10}$ This restricted and delayed access to firm disclosures likely creates information asymmetries among investors even though these SEC filings are deemed to be "public."

To facilitate the timely dissemination of corporate filings through the internet, the SEC developed the EDGAR system which enabled registered firms to file electronically. On February 23, 1993, the SEC released the phase-in schedule for the mandatory implementation of the EDGAR system (SEC Release No. 33-6977). In this schedule, all SEC-registered firms were divided into ten groups, and each group was required to submit corporate filings electronically through the EDGAR system after the respective implementation date. The assignments of firms into the ten phase-in groups were solely based on firm size, where larger firms were required to start filing electronically earlier than smaller firms (SEC Release No. 33-6944). ${ }^{11}$ According to the

\footnotetext{
${ }^{8}$ See "S.E.C. Data: Difficult Hunt" by the New York Times (May 19, 1982).

${ }^{9}$ Chang, Ljungqvist, and Tseng (2020) note that Mead Data Central charged "a fee of $\$ 125$ per month, plus a connect charge of $\$ 39$ an hour, plus a charge of 2.5 cents per line of data plus search charges which range from $\$ 6$ to $\$ 51$ per search." Dialog charged "\$84 per hour plus \$1 per page." See http://www.bio.net/bionet/mm/ag-forst/1992January/000187.html.

${ }^{10}$ D'Souza, Ramesh, and Shen (2010) show that EDGAR decreased the Compustat's median collection lag by 50 percent (i.e., from 22 weekdays to 11 weekdays).

${ }^{11}$ Chang, Ljungqvist, and Tseng (2020, p. 2) note: "In private correspondence, Scott Bauguess, then Acting Chief Economist of the SEC, informed us that the wave assignments were determined solely on the basis of firm size." Gao and Huang (2020) further note that very few firms (3\% of sample firms) deviated from the SEC's phase-in schedule. Thus, the prespecified timing is a strong instrument for the actual timing of the EDGAR implementation and has the advantage of not being contaminated by firms' endogenous decisions.
} 
schedule, firms in the first group (i.e., Group CF-01) were required to start filing through the EDGAR system in April 1993, while firms in the last group (i.e., Group CF-10) were required to do so in May 1996. ${ }^{12}$ The detailed implementation dates for the ten groups are tabulated in Appendix A.

\subsection{Sample}

To construct the sample for our analysis, we obtain the list of firms in these ten groups from the SEC Release No. 33-6977. This list contains each firm's Central Index Key (CIK), which we use to match these firms to Compustat. Our sample period starts in the second quarter of 1991 (i.e., two years before the implementation date of the first phase-in group) and ends in the second quarter of 1998 (i.e., two years after the implementation date of the last phase-in group). We obtain financial statement data from Compustat, stock price and return data from the Center for Research in Security Prices (CRSP), intraday transaction data from NYSE Trade and Quote (TAQ), and data on institutional ownership from Thomson Reuters. Following prior research (e.g., Chen, Goldstein, and Jiang 2007), we exclude firms in the financial and utility industries as well as firms with total assets less than $\$ 10$ million in 1992 (i.e., the last year prior to the EDGAR implementation). Our final sample consists of 3,020 firms and 66,628 firm-quarter observations.

\subsection{Empirical Specification}

Our baseline equation for testing the effect of the EDGAR implementation on the level of corporate investment is as follows:

$$
\operatorname{INVESTMENT}_{i, t+1}=\alpha_{t}+\eta_{i}+\gamma_{1} E D G A R_{i, t}+\gamma_{2} Q_{i, t}+\gamma_{3} C F_{i, t}+\gamma_{4} S I Z E_{i, t}+\varepsilon_{i, t+1}
$$

\footnotetext{
${ }^{12}$ After completing the phase-in of the first four groups in December 1993, the SEC refrained from further phase-in of EDGAR filers over the first half of 1994 while evaluating EDGAR's performance. On December 19, 1994, the SEC issued Release No. 33-7122, which revised the phase-in dates for Group CF-05 and Group CF-06 (from August and November 1994 as in Release No. 33-6977 to January and March 1995, respectively) and confirmed the phase-in dates for the remaining four groups. Our analysis is based on the finalized implementation dates.
} 
where INVESTMENT $T_{i, t+1}$ is firm $i$ 's investment in quarter $t+1$, and $\alpha_{t}$ and $\eta_{i}$ represent yearquarter and firm fixed effects, respectively. Specifically, INVESTMENT $T_{i, t+1}$ is defined as firm $i$ 's capital expenditure in quarter $t+1$ scaled by its net property, plant, and equipment at the end of quarter $t . E D G A R_{i, t}$ is an indicator variable that equals one if firm $i$ is a mandatory EDGAR filer in quarter $t$, and zero otherwise. Following prior research (Foucault and Frésard 2012, 2014), we control for three variables known to correlate with a firm's investment decisions: $Q_{i, t}$ is Tobin's $\mathrm{Q}$ of firm $i$ measured at the end of quarter $t . C F_{i, t}$ is the operating cash flow of firm $i$ in quarter $t$, scaled by lagged book assets. $S I Z E_{i, t}$ is the natural logarithm of the book value of total assets of firm $i$ measured at the end of quarter $t .^{13}$

$\gamma_{1}$ is the diff-in-diff estimator and captures the effect of the EDGAR implementation on the level of corporate investment. We predict a positive $\gamma_{1}$ due to improved equity financing for at least three reasons. First, more timely and extensive dissemination of firm disclosures can reduce adverse selection problems resulting from information asymmetry between the firm and new investors in the primary market (Myers and Majluf 1984). Second, broad information dissemination levels the playing field, mitigates information asymmetry among investors, attracts liquidity to the secondary market, and eventually results in a lower cost of capital in the primary market (Merton 1987; Diamond and Verrecchia 1991). Third, a firm's commitment for timely dissemination of information regarding managers' actions after equity issuance alleviates investors' ex ante concern about ex post moral hazard costs and increases their willingness to provide financing to firms (Jensen and Meckling 1976; Holmström 1979; Watts and Zimmerman 1986). ${ }^{14}$

\footnotetext{
${ }^{13}$ Our inferences are unchanged when we use the natural logarithm of the market capitalization at the end of quarter $t$ to proxy for firm size (see Table A1 of the online appendix). Since we are interested in the investment-to-price sensitivity where Tobin's Q is the (normalized) price measure, we avoid using another price-based measure of firm size in our main analysis.

${ }^{14}$ For example, Shroff (2020) provides evidence on the value of the Public Company Accounting Oversight Board inspections in mitigating financing frictions for non-U.S. companies.
} 
While it is difficult to empirically separate these different explanations, they point to the same prediction that reduced costs of accessing firm disclosures lead to an increased level of equity financing and investment.

Two things are worth noting. First, the assignments of firms into the ten phase-in groups were solely based on a snapshot of pre-EDGAR market capitalization (Chang, Ljungqvist, and Tseng 2020). Equation (1) does not include a control for pre-EDGAR market capitalization because it is subsumed by firm fixed effects. Second, the time-varying firm characteristics (i.e., $Q_{i, t}, C F_{i, t}$, and $\left.S I Z E_{i, t}\right)$ are likely affected by the EDGAR implementation and controlling for them might confound the estimate of the effect of the EDGAR implementation on investment (Angrist and Pischke 2009; Gao and Huang 2020). ${ }^{15}$ Hence, we run all our regressions without and with controlling for time-varying firm characteristics. We cluster standard errors by firm given multiple quarterly observations for each firm (Petersen 2009).

To examine how the EDGAR implementation affects the investment-to-price sensitivity, we augment Equation (1) by interacting $E D G A R_{i, t}$ with $Q_{i, t}, C F_{i, t}$, and $S I Z E_{i, t}$ as follows:

$$
\begin{aligned}
& \operatorname{INVESTMENT}_{i, t+1} \\
& \qquad \begin{array}{l}
=\alpha_{t}+\eta_{i}+\gamma_{1} E D G A R_{i, t}+\gamma_{2} Q_{i, t}+\gamma_{3} C F_{i, t}+\gamma_{4} \operatorname{SIZE}_{i, t}+\gamma_{5} Q_{i, t} \times E D G A R_{i, t} \\
\\
+\gamma_{6} C F_{i, t} \times E D G A R_{i, t}+\gamma_{7} \operatorname{SIZE}_{i, t} \times E D G A R_{i, t}+\varepsilon_{i, t+1}
\end{array}
\end{aligned}
$$

where $\gamma_{5}$ captures the effect of the EDGAR implementation on the investment-to-price sensitivity. We do not have a signed prediction for $\gamma_{5}$ because it depends on how the EDGAR implementation affects revelatory price efficiency, which is ex ante unclear. To clarify this idea, we develop a stylized model in the next section to highlight the basic mechanism.

\footnotetext{
${ }^{15}$ Gormley and Matsa (2016) illustrate the importance of excluding endogenous controls (e.g., firm size) when examining the effects of business combination laws. They note: "For example, prior studies of how BC laws affect firms' acquisition activity have included a time-varying control for firm size. But, presumably, if passage of the BC law affects acquisitions, it also affects firm size, making firm size an invalid control” (p. 443).
} 


\section{Theoretical Framework for Managerial Learning}

Let a representative firm's value be given by $\theta K-\frac{1}{2} K^{2}$, where $K$ is the total capital, and $\theta$ is the random variable that captures the level of productivity of the firm's capital. $\theta$ can be interpreted as the firm's fundamentals. Suppose that $\theta$ is normally distributed with mean 0 and variance $\frac{1}{\mu_{\theta}}$. Given the firm's value function, it is easy to see that the firm manager's optimal capital level at time $t$ equals the expected level of $\theta$, i.e., $K_{t}=E(\theta \mid$ Manager's Information at $t)$. Changes from $K_{t}$ to $K_{t+1}$ take the form of investment during period $t+1$. Here, the value function is assumed to be concave in total capital $K$, and for simplicity, we implicitly assume that adjustments to $K$ are costless. Introducing some adjustment costs will not affect the results qualitatively.

For simplicity and without loss of generality, we focus on a model of two periods: 0 and 1. At $t=0$, the price of the firm's stock reflects the prior belief about the firm's fundamental $\theta$. The manager of the firm privately observes a signal about $\theta$, denoted as $M$, where $M=\theta+\varepsilon_{M}$, and $\varepsilon_{M} \sim N\left(0, \frac{1}{\mu_{M}}\right)$. Given her information and using Bayesian updating, the firm's manager will optimally set the level of capital $K_{0}$ at: $K_{0}=E(\theta \mid$ prior,$M)=\frac{\mu_{M}}{\mu_{\theta}+\mu_{M}} M$.

At $t=1$, there are two pieces of information in the marketplace. The first piece of information is a noisy signal about the manager's private information $M$. We denote this signal as $M^{\prime}$, where $M^{\prime}=M+\varepsilon_{M^{\prime}}$, and $\varepsilon_{M^{\prime}} \sim N\left(0, \frac{1}{\mu_{M^{\prime}}}\right)$. The second piece of information is an independent signal about the fundamentals $\theta$. We denote this signal as $N$, where $N=\theta+\varepsilon_{N}$, and $\varepsilon_{N} \sim N\left(0, \frac{1}{\mu_{N}}\right)$. These two signals reflect the different types of information markets can have. One is information that is already known to the manager (i.e., a signal about the manager's information), 
and the other is information that is new to the manager (i.e., an independent signal about the fundamentals). Both types of signals can be observed by the market maker in various ways. The most common ways are via the order flows of traders, and via public releases of information. Here we assume for concreteness that both signals are observed by the market maker, who then sets the price to equal the expected level of $\theta$, i.e., $P_{t}=E(\theta \mid$ Market Maker's Information at $t) .{ }^{16}$ More specifically, $P_{1}=E\left(\theta \mid\right.$ prior $\left., M^{\prime}, N\right)=\frac{\mu_{N}}{\mu_{\theta}+\mu_{N}+\frac{\mu_{M} \mu_{M^{\prime}}}{\mu_{M}+\mu_{M^{\prime}}}} N+\frac{\frac{\mu_{M} \cdot \mu_{M^{\prime}}}{\mu_{M}+\mu_{M^{\prime}}}}{\mu_{\theta}+\mu_{N}+\frac{\mu_{M} \mu_{M^{\prime}}}{\mu_{M^{+}+\mu_{M^{\prime}}}}} M^{\prime}$.

The manager observes the price $\left(P_{1}\right)$ and the information in the market about her own signal $\left(M^{\prime}\right)$, hence she can infer from price the independent signal in the market about the fundamentals $(N)$. She then optimally sets $K_{1}$ at: $K_{1}=E(\theta \mid$ prior, $M, N)=\frac{\mu_{N}}{\mu_{\theta}+\mu_{N}+\mu_{M}} N+\frac{\mu_{M}}{\mu_{\theta}+\mu_{N}+\mu_{M}} M$. Then, investment during period $t=1\left(I_{1}\right)$ is the difference between total capital at $t=1\left(K_{1}\right)$ and total capital at $t=0\left(K_{0}\right)$. Hence: $I_{1}=\frac{\mu_{N}}{\mu_{\theta}+\mu_{N}+\mu_{M}} N+\frac{\mu_{M}}{\mu_{\theta}+\mu_{N}+\mu_{M}} M-\frac{\mu_{M}}{\mu_{\theta}+\mu_{M}} M=\frac{\mu_{N}}{\mu_{\theta}+\mu_{N}+\mu_{M}}(N-$ $\left.\frac{\mu_{M}}{\mu_{\theta}+\mu_{M}} M\right)$

We are interested in the sensitivity of $I_{1}$ to $P_{1}\left(\frac{d I_{1}}{d P_{1}}\right)$. As econometricians, we observe $I_{1}$ and $P_{1}$, but not $N$ or $M$. To derive the sensitivity of $I_{1}$ to $P_{1}$, we can write $N$ and $M$ as the products of the following latent linear projections on $P_{1}: M=\gamma_{M} P_{1}+e_{M}$, and $N=\gamma_{N} P_{1}+e_{N}$. Then, we get: $\frac{d I_{1}}{d P_{1}}=\frac{\mu_{N}}{\mu_{\theta}+\mu_{N}+\mu_{M}}\left(\frac{d N}{d P_{1}}-\frac{\mu_{M}}{\mu_{\theta}+\mu_{M}} \frac{d M}{d P_{1}}\right)=\frac{\mu_{N}}{\mu_{\theta}+\mu_{N}+\mu_{M}}\left(\gamma_{N}-\frac{\mu_{M}}{\mu_{\theta}+\mu_{M}} \gamma_{M}\right)$.

By rule of linear projections, $\gamma_{N}=\frac{\operatorname{Cov}\left(P_{1}, N\right)}{\operatorname{Var}\left(P_{1}\right)}$ and $\gamma_{M}=\frac{\operatorname{Cov}\left(P_{1}, M\right)}{\operatorname{Var}\left(P_{1}\right)}$. Thus, our model predicts: $\frac{d I_{1}}{d P_{1}}=\frac{1}{\operatorname{Var}\left(P_{1}\right)} \frac{\mu_{N}}{\mu_{\theta}+\mu_{N}+\mu_{M}}\left(\operatorname{Cov}\left(P_{1}, N\right)-\frac{\mu_{M}}{\mu_{\theta}+\mu_{M}} \operatorname{Cov}\left(P_{1}, M\right)\right)$. Given the model structure, we can

\footnotetext{
${ }^{16}$ In this simple model, the price the market maker sets does not take into account its feedback effect on manager's action. For models that consider this feedback loop, see Goldstein and Guembel (2008) and Edmans, Jiang, and Goldstein (2015).
} 
derive expressions for $\operatorname{Var}\left(P_{1}\right), \operatorname{Cov}\left(P_{1}, N\right)$ and $\operatorname{Cov}\left(P_{1}, M\right)$ (see the detailed derivations in Appendix B). Substituting these expressions and after some algebra, we get: $\frac{d I_{1}}{d P_{1}}=$ $\frac{\mu_{N}}{\left[\mu_{N}+\frac{\mu_{M^{\prime} \mu_{M^{\prime}}}}{\mu_{M^{+}+\mu_{M^{\prime}}}}\right]} \frac{\mu_{\theta}}{\mu_{\theta}+\mu_{M}}$.

The above expression shows that the sensitivity of investment to price (1) is increasing in the precision of the information in the price that is new to the manager $\left(\mu_{N}\right) ;(2)$ is decreasing in the precision of the information in the price that is already known to the manager $\left(\mu_{M^{\prime}}\right)$; and (3) is decreasing in the precision of managerial information $\left(\mu_{M}\right)$.

The intuition behind these results goes as follows: Two types of information affect the price, one is new to the manager, and the other is already known to her. The manager will adjust the optimal capital level (i.e., invest) only upon information in the price that is new to her. The information that was already known to her affected her past capital level and will not affect current investment. Thus, the sensitivity of investment to price will be stronger when movements in the price are more likely to originate from information that is new to the manager than from information that was already known to her. A high precision of new information in the price (which is equivalent to a high amount of new information in the price) will generate a stronger sensitivity of investment to price, while a high precision of old information (which is equivalent to a high amount of old information) will generate a weaker sensitivity. Finally, when the manager's private information is more precise, it is less likely that new information in price changes her expectation about $\theta$ and affects her investment decision, resulting in a lower sensitivity of the investment to the price.

Thus, the model suggests that the precision of information in price (or, the amount of total information in price) is not necessarily positively correlated with the investment sensitivity to price. 
The type of information matters a lot. Overall, we believe the insight is more general than the specific formulation of this model. The distinction between information that is new to managers and information that managers already had is critical. The incorporation of more information of the first type ( $N$ in the model) into the price will increase the sensitivity of investment to price, while the incorporation of more information of the second type $\left(M^{\prime}\right.$ in the model) will decrease this sensitivity.

In the empirical setting of the EDGAR implementation, prior research finds that analyst forecast accuracy and stock pricing efficiency increase significantly after a firm becomes an EDGAR filer (Gao and Huang 2020). This result suggests that the precision of information in the marketplace (or, the amount of total information in the marketplace) increases after the EDGAR shock. However, this increase in total information can be entirely driven by the piece of information that is already known to the manager (i.e., $M^{\prime}$ in the model). ${ }^{17}$ Hence, this result does not speak to how the EDGAR shock would affect the amount of information that is new to the manager ( $N$ in the model), which is the focus of our empirical analysis.

Another implication from the model is that the extent to which the manager can learn from the market depends on the precision of her private information ( $M$ in the model). When $M$ is very precise, it is less likely that the EDGAR implementation will affect her investment decisions through the learning channel. We expect the precision of $M$ to be relatively high for assets in place and relatively low for growth options. Therefore, if the EDGAR implementation affects the investment-to-price sensitivity through the managerial learning channel, we should observe a stronger effect in growth firms than in value firms.

\footnotetext{
${ }^{17}$ As noted in the Introduction, increased information dissemination after the EDGAR shock is likely the primary, but not necessarily the only, reason for the change in $M^{\prime}$ in the marketplace.
} 


\section{Main Analysis}

\subsection{Descriptive Statistics}

Table 1 reports the descriptive statistics for the variables used in our main analysis. All continuous variables are winsorized at the top and bottom one percent to mitigate the influence of extreme values. Panel A presents the summary statistics for the sample. INVESTMENT exhibits reasonable variations in the sample; and its mean, median, and standard deviation are 7.1\%, 4.9\%, and $7.6 \%$, respectively. We have a roughly equal number of firm-quarter observations before and after the EDGAR implementation (50.6\% versus 49.4\%). The average and median Tobin's Q are 1.8 and 1.4, respectively. Panel B presents the Pearson (above diagonal) and Spearman (below diagonal) correlations for the variables used in our empirical analysis. We observe a strong positive correlation between INVESTMENT and Tobin's Q (Pearson correlation of 0.28 and Spearman correlation of 0.33$)$.

\subsection{Main Results on Corporate Investment}

We analyze the effect of the EDGAR implementation on corporate investment by estimating Equations (1) and (2). Table 2 reports the main regression results. In column 1, we only include $E D G A R$ as the independent variable, along with firm and year-quarter fixed effects. The coefficient on EDGAR is 0.613 ( $p$-value $<0.01$ ), which represents a $9 \%$ increase relative to the sample mean of INVESTMENT. In column 2, we control for Tobin's $\mathrm{Q}(Q)$, cash flows $(C F)$, and firm size $(S I Z E)$, and the coefficient on EDGAR remains significantly positive ( $p$-value $<0.01$ ). These results confirm the conventional wisdom that the EDGAR implementation reduces adverse selection and moral hazard problems and leads to an increase in the level of corporate investment.

In column 3 of Table 2, we report the results of the regression model in Equation (2). The coefficient on $Q$ measures the investment-to-price sensitivity prior to the EDGAR implementation 
and is 1.908 ( $p$-value $<0.01)$. The coefficient on $Q \times E D G A R$ measures the change in the sensitivity of investment to price after the EDGAR shock and is -0.392 ( $p$-value $<0.01)$. Comparing these two coefficients suggests that the EDGAR implementation leads to a $20 \%$ decline in the investmentto-price sensitivity. This observed decrease in the investment-to-price sensitivity cannot be explained by reduced adverse selection or moral hazard after the EDGAR implementation because these channels should make firms more responsive to their investment opportunities. Instead, this result suggests that EDGAR inclusion leads to a crowding-out effect and reduces managerial learning from prices.

Interestingly, the coefficients on $C F$ and $C F \times E D G A R$ are both significantly positive. Since a firm's cash flows are informative about its performance and investment opportunities (Alti 2003; Heitzman and Huang 2019), these results suggest that managers increase their reliance on internal profit signals (i.e., $C F$ ) and decrease their reliance on external price signals (i.e., $Q$ ) after the EDGAR implementation.

\subsection{Parallel Trends}

The diff-in-diff approach does not require ex ante firm characteristics (e.g., firm size) to be identical between the treatment and control groups as any systematic difference between them will be eliminated in the estimation (through firm fixed effects). In Table A2 of the online appendix, we further augment Equation (2) by interacting $Q$ with firm fixed effects to allow the investmentto-price sensitivity to vary across firms. The coefficient on $Q \times E D G A R$ remains significantly negative $(p$-value $<0.05)$.

One important identifying assumption for the diff-in-diff estimates is that the treatment and control groups follow parallel trends in the absence of the EDGAR treatment. A common way to assess the plausibility of this parallel-trends assumption is to check whether the treatment and 
control groups share similar trends prior to the treatment. Following Foucault and Frésard (2012), we plot the dynamic diff-in-diff estimates (along with the 95\% confidence intervals) of the effects of the EDGAR implementation on the investment level and the investment-to-price sensitivity in Figures 1 and 2, respectively. Figure 1 shows that the level of investment is not statistically different between the treatment and control groups in the two quarters before the EDGAR implementation. Figure 2 shows a similar pattern of no differential pre-trends for the investmentto-price sensitivity. The estimates in these two figures provide support for the parallel-trends assumption. Moreover, Figure 1 and Figure 2 show that both treatment effects are rather persistent and do not exhibit any reversal in the quarters after the EDGAR shock.

Overall, the evidence in Table 2 and Figures 1 and 2 suggests that EDGAR inclusion results in an increase in the level of investment and a decline in the investment-to-price sensitivity. To provide further evidence on the underlying mechanisms, we examine the equity financing channel and the managerial learning channel in the next section.

\section{Analysis of Mechanisms}

\subsection{Equity Financing Channel}

We analyze the equity financing channel through which the EDGAR implementation affects the level of corporate investment. We estimate the regression model in Equation (3):

$\operatorname{DEPVAR}_{i, t}=\alpha_{t}+\eta_{i}+\beta_{1} E D G A R_{i, t}+\beta_{2} S I Z E_{i, t-1}+\beta_{3} P R C_{-} I N V_{i, t-1}+\varepsilon_{i, t}$

where $D E P V A R_{i, t}$ represents the bid-ask spread estimator (ILLIQUID) derived from daily high and low prices following Corwin and Schultz (2012), idiosyncratic return volatility (IVOL) based on the market model, and the amount of equity issuance (EQUITY). 
The high-low spread estimator (ILLIQUID) captures transitory volatility at the daily level and closely approximates the cost of immediacy. ${ }^{18}$ A higher ILLIQUID indicates a higher level of stock illiquidity. Corwin and Schultz (2012) show that it generally outperforms other lowfrequency estimators and works particularly well in the 1993-1996 period when the minimum tick was one-eighth. The idiosyncratic return volatility (IVOL) reflects information asymmetry between firm managers and the market in a framework in which the total uncertainty about a firm is decomposed into market-wide and firm-specific components (Dierkens 1991; Moeller, Schlingermann, and Stulz 2007; Kim, Li, Pan, and Zuo 2013). ${ }^{19}$

Following Jayaraman and $\mathrm{Wu}$ (2019), we include two basic controls. SIZE $E_{i, t-1}$ is the lagged firm size (the natural logarithm of total assets), and $P R C_{-} I N V_{i, t-1}$ is the inverse of stock price measured at the end of quarter $t-1$. Year-quarter fixed effects $\left(\alpha_{t}\right)$ and firm fixed effects $\left(\eta_{i}\right)$ are included. We run our regressions without and with controlling for time-varying firm characteristics, and the specification without these endogenous controls is our preferred one.

Panel A of Table 3 reports the regression results. We include only EDGAR as the independent variable in the odd columns and add firm size (SIZE) and the inverse of stock price $\left(P R C_{-} I N V\right)$ as controls in the even columns. In columns 1 and 2 of Panel $\mathrm{A}$, the coefficient on EDGAR is significantly negative at the $1 \%$ level, suggesting an improvement in a firm's stock liquidity after the EDGAR shock. The coefficient of -0.278 in column 1 translates into a $16 \%$ reduction (relative to the sample mean) in illiquidity on average. In columns 3 and 4 of Panel A, the coefficient on EDGAR is significantly negative at the $1 \%$ level. The coefficient in column 3 suggests that a firm's idiosyncratic return volatility decreases by 0.128 percentage points after it

\footnotetext{
${ }^{18}$ The cost (or price) of immediacy is the return that dealers must expect to earn in order to provide liquidity promptly and sufficiently (e.g., Dick-Nielsen and Rossi 2019).

${ }^{19}$ Our inferences remain unchanged with alternative measures of illiquidity (e.g., Amihud 2002) or return volatility (e.g., total return volatility or idiosyncratic return volatility based on the Fama-French (1993) three-factor model).
} 
becomes an EDGAR filer. In columns 5 and 6 of Panel A, the dependent variable is the amount of equity financing $(E Q U I T Y)$. The coefficient on EDGAR is significantly positive ( $p$-value $<0.01)$ in both columns. The magnitude is also economically meaningful. The coefficient of 0.294 in column 5 suggests an increase in equity financing by $0.294 \%$ of total assets each quarter on average.

Panel B of Table 3 links these results in Panel A with a path analysis design (e.g., Landsman, Maydew, and Thornock 2012). A path analysis aims to provide estimates of the direct and indirect effects of the source variable (i.e., EDGAR) on the outcome variable (i.e., EQUITY). It is best explained by considering a path diagram (see Figure 3). The indirect effect is the product of the direct path coefficients leading to and from the mediating variable, and its significance is based on the Sobel (1982) test. ${ }^{20}$ In column 1 of Panel B, we find that the indirect effect of EDGAR on EQUITY is significant through the mediating variable ILLIQUID. The product coefficient is 0.063 and statistically significant at the $1 \%$ level. In column 2 of Panel B, we repeat the same path analysis for $I V O L .{ }^{21}$ The product coefficient is 0.009 and statistically significant at the $1 \%$ level. We note that, while the effect of EDGAR on ILLIQUID, IVOL, or EQUITY is plausibly causal, the effect of ILLIQUID or IVOL on EQUITY in the path analysis is subject to endogeneity concerns (e.g., measurement error, omitted variable bias or reverse causality).

Panel C of Table 3 links the EDGAR implementation to investment with a path analysis design, and the corresponding path diagram is plotted as Figure 4 . We find that the indirect effect of EDGAR on INVESTMENT is significant through the mediating variable ILLIQUID, IVOL, or EQUITY. The product coefficient is 0.105 in column $1,0.044$ in column 2, and 0.016 in column 3 . All these coefficients are statistically significant at the 5\% level or better. We again note that the

\footnotetext{
${ }^{20} \mathrm{We}$ use the Stata command sem to estimate a structural equation model (SEM).

${ }^{21}$ We conduct two separate path analyses for ILLIQUID and IVOL because these two variables are strongly correlated (see Panel B of Table 1) and likely to capture the same underlying construct.
} 
relation between INVESTMENT and ILLIQUID, IVOL, or EQUITY is subject to endogeneity concerns, and, thus, these product coefficients should be interpreted with caution.

Collectively, Table 3 provides evidence supporting the equity financing channel: the EDGAR shock leads to an increase in stock market liquidity, a reduction in stock return volatility, and an increase in equity financing and corporate investment.

Our previous analysis focuses on the effect of EDGAR inclusion on equity financing instead of debt financing because the former is more likely to be negatively affected by information asymmetry (Myers and Majluf 1984). Even though the EDGAR implementation reduces the information asymmetry between firms and investors, firms are still likely to follow the pecking order of financing, i.e., using internal funds first, then issuing debt, and lastly raising equity. Thus, the observed increase in equity financing after the EDGAR implementation is unlikely to reflect a substitution of equity for debt. Consistent with this prediction, we find no evidence that the EDGAR implementation affects the amount of debt financing (see Table A3 of the online appendix).

\subsection{Managerial Learning Channel}

\subsubsection{Institutional Ownership}

Gao and Huang (2020) find that trades by retail investors, especially those with access to the internet, become more informative about future stock returns after the EDGAR implementation. This result suggests that retail investors extract useful information from EDGAR filings for their trading purpose. However, we do not expect this information to be new to managers. Further, the EDGAR implementation likely provides greater benefits to retail investors who often lack the resources and skills to acquire information than to institutional investors. Thus, we expect a decline 
in a firm's institutional ownership (as a percentage of total shares outstanding) after it is included in the EDGAR system.

In Panel A of Table 4, we analyze the effect of the EDGAR shock on institutional ownership. The coefficient on EDGAR in column 1 is significantly negative at the 5\% level and translates into a reduction of 0.72 percentage points in institutional ownership (INSTOWN). This result is consistent with our expectation that a firm's inclusion into the EDGAR system reduces the information advantage of some institutional investors and makes its stock relatively more attractive to retail investors.

Not all institutional investors actively trade on information. Prior research on informed trading commonly uses the institutional investor classification developed by Bushee (1998) and focuses on transient institutional investors (who hold small stakes in many firms and trade frequently in and out of stocks) as privately-informed investors (e.g., Ke and Petroni 2004; Ke and Ramalingegowda 2005; Akins, Ng and Verdi 2012). Thus, in columns 3 and 4, we analyze the effect of the EDGAR shock on transient institutional investor ownership (INSTOWN_TRA). The coefficient on EDGAR in column 3 is significantly negative at the 5\% level and translates into a reduction of 0.38 percentage points in transient institutional investor ownership.

In addition, we repeat the regression for the other two types of institutional investors: quasiindexers (who use indexing or buy-and-hold strategies characterized by high diversification and low portfolio turnover) and dedicated institutional investors (who have large, long-term holdings concentrated in only a few firms). These two types of institutional investors do not actively trade on information as transient institutional investors do, and they are unlikely to affect the extent of revelatory price efficiency. In Table A4 of the online appendix, we show that EDGAR inclusion leads to a decrease in quasi-indexer ownership but an increase in dedicated institutional investor 
ownership. The reduced ownership by quasi-indexers is consistent with the idea that EDGAR benefits retail investors more and leads to a disproportionate increase in retail investor ownership. The increased ownership by dedicated institutional investors suggests that EDGAR inclusion potentially reduces monitoring costs to these investors and leads to an increased demand from them. ${ }^{22}$

Together, the results in Panel A of Table 4 and Gao and Huang (2020) suggest that a firm's inclusion into the EDGAR system levels the playing field and makes its stock relatively more attractive to retail investors than to institutional investors who tend to actively trade on information. By making a firm's disclosures more readily available to retail investors, the EDGAR system improves retail investors' information production but potentially discourages institutional investors' private information acquisition. To assess the equilibrium level of private information in prices, we rely on two measures based on structural market microstructure models in the next section.

\subsubsection{Privately Informed Trading}

We use two measures of private information based on structural market microstructure models. While there are no direct measures of revelatory price efficiency, these two measures of private information are likely to be positively correlated with the extent of revelatory price efficiency (Bond, Edmans, and Goldstein 2012). Our first measure is the probability of informed trading $(G P I N)$ based on the Generalized PIN model recently developed in Duarte, Hu, and Young (2020). In the traditional PIN model (Easley, Kiefer, O'Hara, and Paperman 1996), privateinformation arrival is the only cause for increase in expected daily turnover. The GPIN model

\footnotetext{
${ }^{22}$ Increased monitoring by investors post EDGAR is likely to lead to an increase in the investment-to-price sensitivity. The observed decrease in the investment-to-price sensitivity suggests that this net effect is likely driven by reduced managerial learning (instead of increased investor monitoring).
} 
extends the PIN model by allowing expected daily turnover from noise trading to be random. Duarte, $\mathrm{Hu}$, and Young (2020) show that the GPIN model matches the variability of noise trade in the data and identifies private-information arrival much better than other variants of the PIN model.

Our second measure is the adverse selection component of the bid-ask spread (LAMBDA). It represents the magnitude of the revision in the market-maker's beliefs concerning the stock's value induced by order flows, and is estimated as the extent to which stock prices are affected by unexpected order flows (Madhavan, Richardson, and Roomans 1997; Armstrong, Core, Taylor, and Verrecchia 2011). These two measures of private information are complementary as the GPIN measure is entirely based on order flows while the $L A M B D A$ measure relates unexpected order flows to stock price changes.

The results are reported in Panel B of Table 4. The sample size is reduced for these two measures because both rely on intraday transaction data from the NYSE Trade and Quote (TAQ) database whose coverage starts in 1993. Further, the GPIN measure is only computed for NYSE stocks in Duarte, $\mathrm{Hu}$, and Young (2020). ${ }^{23}$ In columns 1 and 2 where the dependent variable is the probability of informed trading (GPIN), the coefficient on EDGAR is significantly negative at the $5 \%$ level. The coefficient of -2.833 in column 1 translates into an $11 \%$ reduction (relative to its sample mean) in GPIN. In columns 3 and 4, we replace the dependent variable with the adverse selection component of the bid-ask spread ( $L A M B D A)$. Similarly, the coefficient on EDGAR is significantly negative at the $1 \%(5 \%)$ level in column 3 (column 4$)$. The coefficient of -0.009 in column 3 translates into a $6 \%$ reduction (relative to its sample mean) in $L A M B D A$. The results in Panel B suggest a reduction in privately informed trading after the EDGAR implementation.

\footnotetext{
${ }^{23}$ We thank Edwin Hu and Daniel Taylor for providing us with the GPIN and LAMBDA measures, respectively.
} 
Prior research also uses price non-synchronicity as a measure of the amount of private information in prices in equilibrium (Chen, Goldstein, and Jiang 2007). We note that the degree of price non-synchronicity is likely driven by the total amount of firm-specific information in prices (from both public and private sources). The result of increased price non-synchronicity after the EDGAR implementation documented in Gao and Huang (2020) suggests that the total amount of firm-specific information increases: the increase in public information dominates the decrease in private information.

\subsubsection{Growth Firms versus Value Firms}

To provide further evidence to support the managerial learning channel, we perform a cross-sectional analysis. To the extent that investors' information advantage lies in evaluating growth options, we expect that EDGAR inclusion is likely to reduce managerial learning to a greater extent in growth firms than in value firms. To perform this test, we divide the full sample of firms into these two types of firms based on the market-to-book ratios in 1992 (i.e., the last year prior to the EDGAR implementation). GROWTH_FIRM (VALUE_FIRM) is an indicator that equals one if a firm's market-to-book ratio in 1992 is above (below) the median, and zero otherwise.

In Panel A of Table 5, we replace EDGAR in Equation (3) with its interactions with the two firm-type indicators. The coefficient on the interaction term EDGAR $\times$ GROWTH_FIRM is significantly negative at the $5 \%$ level or better in all columns. In contrast, the coefficient on the interaction term $E D G A R \times V A L U E \_F I R M$ is statistically insignificant across the board. Further, the difference between the coefficients on these two interaction terms is significant at $10 \%$ level or better in all columns. Thus, the results in Panel A suggest that the negative effects of the EDGAR shock on institutional ownership and privately informed trading are concentrated in growth firms. ${ }^{24}$

\footnotetext{
${ }^{24}$ Our inferences are unchanged when we include the (endogenous) firm-level controls as in Table 4.
} 
In Panel B of Table 5, we repeat the regression on the investment-to-price sensitivity as specified in Equation (2) by replacing $Q \times E D G A R$ with its interactions with $G R O W T H \_F I R M$ and VALUE_FIRM. In column 1, we repeat our previous analysis in Table 2 for this restricted sample (requiring the availability of the market-to-book ratio in 1992) and the coefficient on $Q \times E D G A R$ remains significantly negative at the $1 \%$ level. In column 2 , the coefficient on the interaction term $Q \times E D G A R \times G R O W T H \_F I R M$ is significantly negative at the $1 \%$ level, while the coefficient on $Q \times E D G A R \times V A L U E \_F I R M$ is statistically insignificant. The difference between these two coefficients is significant at the $1 \%$ level. Overall, the observed decline in the investment-to-price sensitivity after the EDGAR shock is concentrated in growth firms, in which managerial learning is expected to be more important.

In Panel C of Table 5, we repeat the analysis on the equity financing channel and the level of investment by replacing EDGAR with its interactions with GROWTH_FIRM and VALUE_FIRM. We find that the observed EDGAR effects on stock liquidity, return volatility, equity financing, and corporate investment are concentrated in value firms. We view these results as descriptive and consistent with the Myers and Majluf (1984) framework in which information asymmetry about assets in place (not growth options) causes adverse selection problems.

\section{Additional Analysis}

\subsection{Firm Performance}

In this section, we investigate the effects of the EDGAR implementation on ex post firm performance. We perform two sets of tests as follows. First, in Panel A of Table 6, we rerun the regression model in Equation (3) by replacing the dependent variable with the return on equity $(R O E)$, return on assets $(R O A)$, and sales growth $(\triangle S A L E S)$. We report the regression results without and with control variables in the odd and even columns, respectively. The coefficient on 
EDGAR is significantly positive at the $5 \%$ level or better in all six columns, suggesting that the EDGAR shock has a positive effect on firm profitability and sales growth. In terms of economic significance, the coefficients in columns 1,3 , and 5 (i.e., $0.388,0.198$, and 2.878) translate into an increase of $9 \%$ in $R O E, 12 \%$ in ROA, and $20 \%$ in $\triangle S A L E S$ (relative to their sample means), respectively. We plot the dynamic diff-in-diff estimates (along with the 95\% confidence intervals) of the effects of the EDGAR implementation on firm performance in Figures A1 to A3 of the online appendix. We observe no difference in pre-trends in firm performance between the treatment and control groups, supporting the parallel-trends assumption. The figures also show that the treatment effects become statistically significant only after a few quarters post the EDGAR shock.

Second, we rerun the same regression but replace $E D G A R$ with $E D G A R \times G R O W T H \_F I R M$ and EDGAR $\times$ VALUE_FIRM in Panel B of Table 6. The coefficient on EDGAR $\times$ VALUE_FIRM is significantly positive at the $1 \%$ level, while the coefficient on EDGAR $\times$ GROWTH_FIRM is negative and statistically insignificant in all columns. The difference between the coefficients on these two interaction terms is significant at the $1 \%$ level in all columns. These results show that the observed improvement in firm profitability and sales growth is concentrated in value firms. ${ }^{25}$

Third, we further divide growth firms into high-growth and low-growth firms and include EDGAR $\times$ HIGH_GROWTH_FIRM and EDGAR $\times L O W \_G R O W T H \_F I R M$ in the regression models in Panel $\mathrm{C}$ of Table 6. The coefficient on EDGAR $\times H I G H \_G R O W T H \_F I R M$ is significantly negative in all columns, while the coefficient on $E D G A R \times L O W \_G R O W T H \_F I R M$ is positive and largely statistically insignificant. The difference between the coefficients on these two interaction terms is significant at the $5 \%$ level or better in all columns. This significant decline in firm

\footnotetext{
${ }^{25}$ In terms of economic significance, the coefficients on $E D G A R \times V A L U E \_F I R M$ in columns 1, 3, and 5 translate into an increase of $25 \%$ in $R O E, 32 \%$ in $R O A$, and $45 \%$ in $\triangle S A L E S$ (relative to their sample means), respectively.
} 
profitability and sales growth in high-growth firms suggests that the negative performance effect of reduced managerial learning dominates the positive performance effect of the EDGAR implementation for these firms. ${ }^{26}$

Collectively, the results in Table 6 reflect the dual effects of greater and broader information dissemination facilitated by modern information technologies. On the one hand, it can better incentivize managers to take value-maximizing actions and improve firm performance. On the other hand, it can hurt firm performance by discouraging privately informed trading and reducing managerial learning from the market. Our evidence suggests that the former effect dominates in value firms while the latter effect dominates in high-growth firms.

\subsection{Robustness Checks}

We conduct two additional analyses to ensure the robustness of our results. First, we repeat our analysis after excluding firms assigned to Group CF-01 as this group contains "transitional" filers that volunteered to file electronically prior to the mandatory phase-in of the EDGAR system in April 1993 (SEC Release No. 33-6977). ${ }^{27}$ Table 7 reports the results for this analysis. Both the magnitude and statistical significance of the coefficients on $Q$ and $E D G A R \times Q$ are quite similar to those reported in Table 2.

Second, we repeat our analysis after redefining the EDGAR indicator for the first four groups to take the value of one if the firm-quarter is after January 17, 1994 (when all electronic EDGAR filings became freely available online via a National Science Foundation grant to New York University) and zero otherwise. Prior to January 17, 1994, electronic EDGAR filings were

\footnotetext{
${ }^{26} \mathrm{We}$ also repeat our analysis in Table 5 for high-growth and low-growth firms and do not find evidence that the EDGAR implementation differentially reduces privately informed trading or the investment-to-price sensitivity for these two types of growth firms. These results suggest that the same degree of reduced managerial learning can be more detrimental to high-growth firms than to low-growth firms.

${ }^{27}$ The SEC started developing an electronic disclosure system in 1983. A pilot system was opened for volunteers filing with the SEC by the fall of 1984. On July 15, 1992, the operational EDGAR system was made available to those filers. See the regulatory overview of electronic filing at: https://www.sec.gov/info/edgar/regoverview.htm.
} 
available through Mead Data Central (a commercial data vendor) for a fee. ${ }^{28}$ Table 8 presents the results and our inferences remain largely unchanged.

\section{Conclusions}

Modern information technologies have greatly facilitated timely dissemination of information to a broad base of investors at low costs. In this paper, we exploit the staggered mandatory implementation of the EDGAR system from 1993 to 1996 as a shock to information dissemination technologies. We find that the EDGAR implementation leads to a $10 \%$ increase in the level of corporate investment but a $20 \%$ decrease in the investment-to-price sensitivity. The increased level of investment is consistent with the conventional wisdom that broader information dissemination leads to an increase in stock liquidity, a decrease in return volatility, and an increase in the level of equity financing. The decreased investment-to-price sensitivity suggests that greater dissemination of corporate disclosures can crowd out private information acquisition and reduce managerial learning from prices. We provide evidence of improved equity financing and reduced managerial learning after the EDGAR implementation. Further, we show that the EDGAR implementation leads to an improvement in performance in value firms but a decline in performance in high-growth firms where learning from the market is particularly important.

Overall, our findings suggest that it is important to consider the tradeoff between financing and learning from prices when evaluating the real effects of modern information technologies. With the rise of FinTech innovation through big data or machine learning techniques, the investing public can now obtain a huge amount of data at relatively low costs (Goldstein, Jiang, and Karolyi 2019). We might reasonably expect the decline in the cost of accessing information to increase forecasting price efficiency. However, our findings suggest that the effect of FinTech innovation

\footnotetext{
${ }^{28}$ See "Plan Opens More Data to Public" by the New York Times (October 22, 1993).
} 
on real efficiency is more nuanced as it might dampen investors' incentives to engage in private information acquisition and reduce managerial learning from prices. Moreover, greater information production and dissemination brought by modern technologies may not necessarily enhance the welfare of investors as they can lead to a reduction in risk-sharing and trading opportunities among investors (Hirshleifer 1971; Kurlat and Veldkamp 2015) and an overweight on public signals due to beauty-contest incentives (Morris and Shin 2002). Evaluating these various tradeoffs brought by FinTech developments is an interesting avenue for future research. 


\section{References}

Akins, B.K., Ng, J., Verdi, R.S., 2012. Investor competition over information and the pricing of information asymmetry. The Accounting Review 87 (1), 35-58.

Alti, A., 2003. How sensitive is investment to cash flow when financing is frictionless? Journal of Finance 58 (2), 707-722.

Amihud, Y., 2002. Illiquidity and stock returns: Cross-section and time-series effects. Journal of Financial Markets 5 (1), 31-56.

Angrist, J.D., Pischke, J.S., 2009. Mostly Harmless Econometrics: An Empiricist's Companion. Princeton University Press.

Armstrong, C.S., Core, J.E., Taylor, D.J., Verrecchia, R.E., 2011. When does information asymmetry affect the cost of capital? Journal of Accounting Research 49 (1), 1-40.

Asthana, S., Balsam, S., Sankaraguruswamy, S., 2004. Differential response of small versus large investors to 10-K filings on EDGAR. The Accounting Review 79 (3), 571-589.

Bai, J., Philippon, T., Savov, A., 2016. Have financial markets become more informative? Journal of Financial Economics 122 (3), 625-654.

Bakke, T.E., Whited, T.M., 2010. Which firms follow the market? An analysis of corporate investment decisions. Review of Financial Studies 23 (5), 1941-1980.

Bernanke, B., Gertler, M., 1990. Financial fragility and economic performance. Quarterly Journal of Economics $105(1), 87-114$.

Bird, A., Karolyi, S.A., Ruchti, T., Truong, P., 2020. More is less: Publicizing information and market feedback. Working Paper. Available at SSRN: https://ssrn.com/abstract=3641837.

Blankespoor, E., deHaan, E., Marinovic, I., 2020. Disclosure processing costs, investors' information choice, and equity market outcomes: A review. Journal of Accounting and Economics, Forthcoming.

Bond, P., Edmans, A., Goldstein, I., 2012. The real effects of financial markets. Annual Review of Financial Economics 4, 339-360.

Bushee, B. 1998. The influence of institutional investors on myopic R\&D investment behavior. The Accounting Review 73 (3), 305-333.

Chang, Y.C., Hsiao, P.J., Ljungqvist, A., Tseng, K., 2020. Testing disagreement models. CEPR Discussion Paper No. DP14677. Available at SSRN: https://ssrn.com/abstract=3489666.

Chang, Y.C., Ljungqvist, A., Tseng, K., 2020. Do corporate disclosures constrain strategic analyst behavior? CEPR Discussion Paper No. DP14678. Available at SSRN: https://ssrn.com/abstract=3594311.

Chen, Q., Goldstein, I., Jiang, W., 2007. Price informativeness and investment sensitivity to stock price. Review of Financial Studies 20 (3), 619-650.

Corwin, S.A., Schultz, P., 2012. A simple way to estimate bid-ask spreads from daily high and low prices. Journal of Finance 67 (2), 719-760.

Dessaint, O., Foucault, T., Frésard, L., Matray, A., 2019. Noisy stock prices and corporate investment. Review of Financial Studies 32 (7), 2625-2672.

Diamond, D.W., 1985. Optimal release of information by firms. Journal of Finance 40 (4), 1071-1094.

Diamond, D.W., Verrecchia, R.E., 1991. Disclosure, liquidity, and the cost of capital. Journal of Finance 46 (4), $1325-1359$. 
Dick-Nielsen, J., Rossi, M., 2019. The cost of immediacy for corporate bonds. Review of Financial Studies 32 (1), 1-41.

Dierkens, N., 1991. Information asymmetry and equity issues. Journal of Financial and Quantitative Analysis 26 (2), 181-200.

D'Souza, J.M., Ramesh, K., Shen, M., 2010. The interdependence between institutional ownership and information dissemination by data aggregators. The Accounting Review 85 (1), 159-193.

Duarte, J., Hu, E., Young, L., 2020. A comparison of some structural models of private information arrival. Journal of Financial Economics 135 (3), 795-815.

Dugast, J., Foucault, T., 2018. Data abundance and asset price informativeness. Journal of Financial Economics 130 (2), 367-391.

Dye, R.A., Sridhar S.S., 2002. Resource allocation effects of price reactions to disclosures. Contemporary Accounting Research 19 (3), 385-410.

Easley, D., Kiefer, N.M., O’Hara, M., Paperman, J.B., 1996. Liquidity, information, and infrequently traded stocks. Journal of Finance 51(4), 1405-1436.

Easley, D., O’Hara, M., 1987. Price, trade size, and information in securities markets. Journal of Financial Economics 19 (1), 69-90.

Edmans, A., Goldstein, I., Jiang, W., 2015. Feedback effects, asymmetric trading, and the limits to arbitrage. American Economic Review 105 (12), 3766-3797.

Edmans, A., Jayaraman, S., Schneemeier, J., 2017. The source of information in prices and investment-price sensitivity. Journal of Financial Economics 126 (1), 74-96.

Fama, E.F., French, K.R., 1993. Common risk factors in the returns on stocks and bonds. Journal of Financial Economics 33 (1), 3-56.

Fama, E.F., Miller, M.H., 1972. The Theory of Finance. New York: Holt, Rinehart, and Winston.

Foucault, T., Frésard, L., 2012. Cross-listing, investment sensitivity to stock price, and the learning hypothesis. Review of Financial Studies 25 (11), 3305-3350.

Foucault, T., Frésard, L., 2014. Learning from peers' stock prices and corporate investment. Journal of Financial Economics 111 (3), 554-577.

Gao, M., Huang, J., 2020. Informing the market: The effect of modern information technologies on information production. Review of Financial Studies 33 (4), 1367-1411.

Gao, P., Liang, P.J., 2013. Informational feedback, adverse selection, and optimal disclosure policy. Journal of Accounting Research 51 (5), 1133-1158.

Glosten, L.R., Milgrom, P.R., 1985. Bid, ask and transaction prices in a specialist market with heterogeneously informed traders. Journal of Financial Economics 14 (1), 71-100.

Goldstein, I., Guembel, A., 2008. Manipulation and the allocational role of prices. Review of Economic Studies $75(1), 133-164$.

Goldstein, I., Jiang, W., Karolyi, G.A., 2019. To FinTech and beyond. Review of Financial Studies 32 (5), 16471661.

Goldstein, I., Yang, L., 2015. Information diversity and complementarities in trading and information acquisition. Journal of Finance 70 (4), 1723-1765. 
Goldstein, I., Yang, L., 2017. Information disclosure in financial markets. Annual Review of Financial Economics 9, 101-125.

Goldstein, I., Yang, L., 2019. Good disclosure, bad disclosure. Journal of Financial Economics 131 (1), 118138.

Gomez, E., 2020. The effect of mandatory disclosure dissemination on information asymmetry: Evidence from the implementation of the EDGAR System. Working Paper. Available at SSRN: https://papers.ssrn.com/abstract id=3577162.

Gormley, T.A., Matsa, D.A., 2016. Playing it safe? Managerial preferences, risk, and agency conflicts. Journal of Financial Economics 122 (3), 431-455.

Griffin, P.A., 2003. Got information? Investor response to form 10-K and form 10-Q EDGAR filings. Review of Accounting Studies 8 (4), 433-460.

Grossman, S.J., Stiglitz, J.E., 1980. On the impossibility of informationally efficient markets. American Economic Review 70 (3), 393-408.

Guo, F., Lisic, L. L., Stuart, M. D., Wang, C., 2019. The impact of information technology on stock price crash risk: Evidence from the EDGAR implementation. Working Paper. Available at SSRN: https://papers.ssrn.com/abstract_id=3223521.

Hayek, F.A., 1945. The use of knowledge in society. American Economic Review 35 (4), 519-530.

Heitzman, S., Huang, M., 2019. Internal information quality and the sensitivity of investment to market prices and accounting profits. Contemporary Accounting Research 36 (3), 1699-1723.

Hirshleifer, J., 1971. The private and social value of information and the reward to inventive activity. American Economic Review 61 (4), 561-574.

Holmström, B., 1979. Moral hazard and observability. Bell Journal of Economics 10 (1), 74-91.

Jayaraman, S., Wu, J.S., 2019. Is silence golden? Real effects of mandatory disclosure. Review of Financial Studies 32 (6), 2225-2259.

Jayaraman, S., Wu, J.S., 2020. Should I stay or should I grow? Using voluntary disclosure to elicit market feedback. Review of Financial Studies 33 (8), 3854-3888.

Jensen, M., Meckling, W.H., 1976. Theory of the firm: Managerial behavior, agency costs and ownership structure. Journal of Financial Economics 3 (4), 305-360.

Kanodia, C., Sapra, H., 2016. A real effects perspective to accounting measurement and disclosure: Implications and insights for future research. Journal of Accounting Research 54 (2), 623-676.

Ke, B., Petroni, K., 2004. How informed are actively trading institutional investors? Evidence from their trading behavior before a break in a string of consecutive earnings increases. Journal of Accounting Research $42(5), 895-927$.

Ke, B., Ramalingegowda, S., 2005. Do institutional investors exploit the post-earnings announcement drift? Journal of Accounting and Economics 39 (1), 25-53.

Kim, Y., Li, S., Pan, C., Zuo, L., 2013. The role of accounting conservatism in the equity market: Evidence from seasoned equity offerings. The Accounting Review 88 (4), 1327-1356.

Kiyotaki, N., Moore, J., 1997. Credit cycles. Journal of Political Economy 105 (2), 211-248.

Kothari, S., So, E.C., Verdi, R., 2016. Analysts' forecasts and asset pricing: A survey. Annual Review of Financial Economics 8, 197-219. 
Kurlat, P., Veldkamp, L., 2015. Should we regulate financial information? Journal of Economic Theory 158 (B), 697-720.

Kyle, A.S., 1985. Continuous auctions and insider trading. Econometrica 53 (6), 1315-1335.

Lai, S., Lin, C., Ma, X., 2020. RegTech adoption and the cost of capital. Working Paper. Available at SSRN: https://papers.ssrn.com/abstract_id=3683046.

Lee, C.M., So, E.C., 2015. Alphanomics: The informational underpinnings of market efficiency. Foundations and Trends ${ }^{\circledR}$ in Accounting 9 (2-3), 59-258.

Leuz, C., Wysocki, P.D., 2016. The economics of disclosure and financial reporting regulation: Evidence and suggestions for future research. Journal of Accounting Research 54 (2), 525-622.

Li, E.X., Ramesh, K., 2009. Market reaction surrounding the filing of periodic SEC reports. The Accounting Review 84 (4), 1171-1208.

Li, W., Qi, Q., 2020. The impact of information technology: information asymmetry, cost of capital and corporate policy. Working Paper. Available at SSRN: https://papers.ssrn.com/abstract_id=3613460.

Lin, T., Liu, Q., Sun, B., 2019. Contractual managerial incentives with stock price feedback. American Economic Review 109 (7), 2446-2468.

Liu, Y., 2019. Information acquisition costs and misreporting: Evidence from the implementation of EDGAR. Working Paper. Available at: https://scholarspace.manoa.hawaii.edu/handle/10125/64860.

Luo, Y., 2005. Do insiders learn from outsiders? Evidence from mergers and acquisitions. Journal of Finance 60 (4), 1951-1982.

Madhavan, A., Richardson, M., Roomans, M., 1997. Why do security prices change? A transaction-level analysis of NYSE stocks. Review of Financial Studies 10 (4), 1035-1064.

Merton, R.C., 1987. A simple model of capital market equilibrium with incomplete information. Journal of Finance 42 (3), 483-510.

Moeller, S.B., Schlingermann, F.P., Stulz, R.M., 2007. How do diversity of opinion and information asymmetry affect acquirer returns? Review of Financial Studies 20 (6), 2047-2078.

Morris, S., Shin, H.S., 2002. Social value of public information. American Economic Review 92 (5), 1521-1534.

Myers, S.C., Majluf, N.S., 1984. Corporate financing and investment decisions when firms have information that investors do not have. Journal of Financial Economics 13 (2), 187-221.

Petersen, M.A., 2009. Estimating standard errors in finance panel data sets: Comparing approaches. Review of Financial Studies 22 (1), 435-480.

Rappaport, A., 1987. Stock market signals to managers. Harvard Business Review. Available at: https://hbr.org/1987/11/stock-market-signals-to-managers.

Roychowdhury, S., Shroff, N., Verdi, R.S., 2019. The effects of financial reporting and disclosure on corporate investment: A review. Journal of Accounting and Economics 68 (2-3), 101246.

Shroff, N., 2020. Real effects of PCAOB international inspections. The Accounting Review 95 (5), 399-433.

Sobel, M.E., 1982. Asymptotic intervals for indirect effects in structural equations models. In: Leinhart, S. (Ed.), Sociological Methodology. Jossey-Bass, San Francisco, 290-312.

Soros, G., 1994. The Alchemy of Finance: Reading the Mind of the Market. New York: John Wiley \& Sons. 
Verrecchia, R.E., 1982. Information acquisition in a noisy rational expectations economy. Econometrica 50 (6), $1415-1430$.

Watts, R.L., Zimmerman, J.L., 1986. Positive Accounting Theory. New Jersey: Prentice-Hall Inc.

Zuo, L., 2016. The informational feedback effect of stock prices on management forecasts. Journal of Accounting and Economics 61 (2-3), 391-413. 
Appendix A: Phase-in Schedule of the EDGAR Implementation

\begin{tabular}{lc}
\hline \hline Implementation Date & Group \\
\hline April 26, 1993 & Phase-in of Group CF-01 \\
July 19, 1993 & Phase-in of Group CF-02 \\
October 4, 1993 & Phase-in of Group CF-03 \\
December 6, 1993 & Phase-in of Group CF-04 \\
January 30, 1995 & Phase-in of Group CF-05 \\
March 6, 1995 & Phase-in of Group CF-06 \\
May 1, 1995 & Phase-in of Group CF-07 \\
August 7, 1995 & Phase-in of Group CF-08 \\
November 6, 1995 & Phase-in of Group CF-09 \\
May 6, 1996 & Phase-in of Group CF-10 \\
\hline \hline Note: This table presents the finalized implementation dates for the ten phase-in groups (SEC Release No. 33- \\
6977 and No. 33-7122).
\end{tabular}




\section{Appendix B: Derivations of $\operatorname{Cov}\left(P_{1}, N\right), \operatorname{Cov}\left(P_{1}, M\right)$, and $\operatorname{Var}\left(P_{1}\right)$}

$$
\begin{aligned}
\operatorname{Cov}\left(P_{1}, N\right) & =\frac{\mu_{N}}{\mu_{\theta}+\mu_{N}+\frac{\mu_{M} \cdot \mu_{M^{\prime}}}{\mu_{M}+\mu_{M^{\prime}}}} \operatorname{Var}(N)+\frac{\frac{\mu_{M} \cdot \mu_{M^{\prime}}}{\mu_{M}+\mu_{M^{\prime}}}}{\mu_{\theta}+\mu_{N}+\frac{\mu_{M} \cdot \mu_{M^{\prime}}}{\mu_{M}+\mu_{M^{\prime}}}} \operatorname{Cov}\left(N, M^{\prime}\right) \\
& \left.=\frac{\mu_{N}}{\mu_{\theta}+\mu_{N}+\frac{\mu_{M} \cdot \mu_{M^{\prime}}}{\mu_{M}+\mu_{M^{\prime}}}\left(\frac{1}{\mu_{\theta}+\mu_{M^{\prime}}}\right.}+\frac{1}{\mu_{N}}\right)+\frac{1}{\mu_{\theta}+\mu_{N}+\frac{\mu_{M} \cdot \mu_{M^{\prime}}}{\mu_{M}+\mu_{M^{\prime}}}} \frac{1}{\mu_{\theta}} \\
& \left.=\left(\frac{\mu_{N}+\mu_{\theta}}{\mu_{\theta}+\mu_{N}+\frac{\mu_{M} \cdot \mu_{M^{\prime}}}{\mu_{M}+\mu_{M^{\prime}}}}+\frac{\mu_{M^{\prime}}}{\mu_{M}+\mu_{M^{\prime}}}\right) \frac{1}{\mu_{\theta}+\mu_{N}+\frac{\mu_{M} \cdot \mu_{M^{\prime}}}{\mu_{M}+\mu_{M^{\prime}}}}\right) \frac{1}{\mu_{\theta}} .
\end{aligned}
$$

$$
\begin{aligned}
& \begin{aligned}
\operatorname{Cov}\left(P_{1}, M\right) & =\frac{\mu_{N} \cdot \mu_{M} \cdot \mu_{M^{\prime}}}{\mu_{\theta}+\mu_{N}+\frac{\mu_{M} \cdot \mu_{M^{\prime}}}{\mu_{M}+\mu_{M^{\prime}}}} \operatorname{Cov}(N, M)+\frac{\frac{\mu_{M}+\mu_{M^{\prime}}}{\mu_{M}+\mu_{N}+\frac{\mu_{M} \cdot \mu_{M^{\prime}}}{\mu_{M}+\mu_{M^{\prime}}}} \operatorname{Cov}}{\mu_{\theta}} \\
& \left.=\frac{\frac{\mu_{M} \cdot \mu_{M^{\prime}}}{\mu_{M}+\mu_{M^{\prime}}}}{\mu_{\theta}+\frac{\mu_{M} \cdot \mu_{M^{\prime}}}{\mu_{M}+\mu_{M^{\prime}}}} \frac{1}{\mu_{\theta}}+\frac{\mu_{\theta}+\mu_{M}}{\mu_{\theta} \mu_{M}}\right)
\end{aligned} \\
& =\frac{1}{\mu_{\theta}}\left(\frac{\mu_{N}+\frac{\mu_{M} \cdot \mu_{M^{\prime}}}{\mu_{M}+\mu_{M^{\prime}}} \frac{\mu_{\theta} \cdot \mu_{M}}{\mu_{M}}}{\mu_{\theta}+\mu_{N}+\frac{\mu_{M} \cdot \mu_{M^{\prime}}}{\mu_{M}+\mu_{M^{\prime}}}}\right) \text {. }
\end{aligned}
$$$$
\operatorname{Var}\left(P_{1}\right)=\left(\frac{\mu_{N}}{\mu_{\theta}+\mu_{N}+\frac{\mu_{M} \cdot \mu_{M^{\prime}}}{\mu_{M}+\mu_{M^{\prime}}}}\right)^{2}\left(\frac{1}{\mu_{\theta}}+\frac{1}{\mu_{N}}\right)
$$$$
+\left(\frac{\frac{\mu_{M} \cdot \mu_{M^{\prime}}}{\mu_{M}+\mu_{M^{\prime}}}}{\mu_{\theta}+\mu_{N}+\frac{\mu_{M} \cdot \mu_{M^{\prime}}}{\mu_{M}+\mu_{M^{\prime}}}}\right)^{2}\left(\frac{1}{\mu_{\theta}}+\frac{1}{\mu_{M}}+\frac{1}{\mu_{M^{\prime}}}\right)
$$$$
+2\left(\frac{\mu_{N}}{\mu_{\theta}+\mu_{N}+\frac{\mu_{M} \cdot \mu_{M^{\prime}}}{\mu_{M}+\mu_{M^{\prime}}}}\right)\left(\frac{\frac{\mu_{M} \cdot \mu_{M^{\prime}}}{\mu_{M}+\mu_{M^{\prime}}}}{\mu_{\theta}+\mu_{N}+\frac{\mu_{M} \cdot \mu_{M^{\prime}}}{\mu_{M}+\mu_{M^{\prime}}}}\right) \frac{1}{\mu_{\theta}}
$$$$
=\frac{\mu_{N} \frac{\mu_{\theta}+\mu_{N}}{\mu_{\theta}}+\left(\frac{\mu_{M} \cdot \mu_{M^{\prime}}}{\mu_{M}+\mu_{M^{\prime}}}\right)^{2}\left(\frac{1}{\mu_{\theta}}+\frac{1}{\mu_{M}}+\frac{1}{\mu_{M^{\prime}}}\right)+2 \frac{\mu_{N}}{\mu_{\theta}} \frac{\mu_{M} \cdot \mu_{M^{\prime}}}{\mu_{M}+\mu_{M^{\prime}}}}{\left(\mu_{\theta}+\mu_{N}+\frac{\mu_{M} \cdot \mu_{M^{\prime}}}{\mu_{M}+\mu_{M^{\prime}}}\right)^{2}}
$$

$$
\begin{aligned}
= & \frac{1}{\mu_{\theta}}\left[\mu_{N}\left(\mu_{\theta}+\mu_{N}\right)+\left(\frac{\mu_{M} \cdot \mu_{M^{\prime}}}{\mu_{M}+\mu_{M^{\prime}}}\right)\left(\left(\frac{\mu_{M} \cdot \mu_{M^{\prime}}}{\mu_{M}+\mu_{M^{\prime}}}\right)+\mu_{\theta}+\mu_{N}\right)+\mu_{N} \frac{\mu_{M} \cdot \mu_{M^{\prime}}}{\mu_{M}+\mu_{M^{\prime}}}\right] \\
= & \frac{1}{\mu_{\theta}} \frac{\mu_{N}+\frac{\mu_{M} \cdot \mu_{M^{\prime}}}{\mu_{M}+\mu_{M^{\prime}}}}{\left(\mu_{\theta}+\mu_{N}+\frac{\mu_{M} \cdot \mu_{M^{\prime}}}{\mu_{M}+\mu_{M^{\prime}}}\right)^{2}} .
\end{aligned}
$$


Appendix C: Variable Definitions

\begin{tabular}{|c|c|}
\hline Variable & Definition \\
\hline EDGAR & $\begin{array}{l}=\text { An indicator that equals one after a firm becomes a mandatory EDGAR filer, } \\
\text { and zero otherwise. }\end{array}$ \\
\hline INVESTMENT & $\begin{aligned} &= \text { Capital expenditure scaled by lagged net property, plant, and equipment } \\
& \text { (PPENTQ). Compustat quarterly data provide year-to-date net capital } \\
& \text { expenditure (CAPXY). We therefore set quarterly capital expenditure to be } \\
& \text { CAPXY (in the first fiscal quarter) or the change in CAPXY (in the second, } \\
& \text { third, and fourth fiscal quarters). It is expressed in percentage points. }\end{aligned}$ \\
\hline$Q$ & $\begin{aligned} &= \text { The book value of total assets (ATQ) minus the book value of equity (CEQQ) } \\
& \text { plus the market value of equity (CSHOQ } \times \text { PRCCQ), scaled by the book value } \\
& \text { of total assets (ATQ). }\end{aligned}$ \\
\hline SIZE & $=$ The natural logarithm of the book value of total assets (ATQ). \\
\hline$C F$ & $\begin{aligned}= & \text { Operating cash flows (IBQ+DPQ) scaled by lagged total assets (ATQ). It is } \\
& \text { expressed in percentage points. }\end{aligned}$ \\
\hline PRC_INV & $=$ The inverse of the stock price (PRCCQ) at the fiscal quarter end. \\
\hline ILLIQUUID & $\begin{array}{l}=\text { The bid-ask spread estimated from daily high and low prices following Corwin } \\
\text { and Schultz (2012). Specifically, it is the estimate of a stock's bid-ask spread } \\
\text { as a function of the high-to-low price ratio for a single two-day period and the } \\
\text { high-to-low ratios for two consecutive single days. It is expressed in } \\
\text { percentage points. }\end{array}$ \\
\hline IVOL & $\begin{array}{l}=\text { The standard deviation of the residuals of the market model estimated using } \\
\text { the daily stock returns over the quarter. It is expressed in percentage points. }\end{array}$ \\
\hline EQUITY & $\begin{array}{l}=\text { Equity issuance (SSTKQ) scaled by lagged total assets (ATQ). It is expressed } \\
\text { in percentage points. }\end{array}$ \\
\hline INSTOWN & $=$ Percentage of shares held by institutional investors at the quarter end. \\
\hline INSTOWN_TRA & $\begin{aligned} &= \text { Percentage of shares held by transient institutional investors at the quarter end. } \\
& \text { The classification of transient institutional investors is obtained from the } \\
& \text { institutional investor database developed by Bushee (1998). }\end{aligned}$ \\
\hline GPIN & $\begin{array}{l}=\text { The quarterly average of the conditional probability of private information } \\
\text { arrival on a given day estimated in the Generalized PIN model by Duarte, Hu, } \\
\text { and Young (2020). It is expressed in percentage points. }\end{array}$ \\
\hline$\angle A M B D A$ & $\begin{array}{l}=\text { The quarterly average of the adverse selection component of the bid-ask spread } \\
\text { estimated in Armstrong, Core, Taylor, and Verrecchia (2011) and expressed in } \\
\text { percentage points. }\end{array}$ \\
\hline GROWTH_FIRM & $\begin{array}{l}=\text { An indicator that equals one if a firm's market-to-book ratio in } 1992 \text { is above } \\
\text { the sample median, and zero otherwise. Market-to-book ratio is defined as the } \\
\text { ratio of the market value of a firm's common stock (CSHO×PRCC) to its book } \\
\text { value (CEQ). It is set to missing if CEQ is negative. }\end{array}$ \\
\hline VALUE_FIRM & $\begin{array}{l}=\text { An indicator that equals one if a firm's market-to-book ratio in } 1992 \text { is below } \\
\text { the sample median, and zero otherwise. }\end{array}$ \\
\hline$R O E$ & $\begin{array}{l}=\text { The ratio of operating income before depreciation (OIBDPQ) to lagged book } \\
\text { value of equity (CEQQ), expressed in percentage points. It is set to missing if } \\
\text { the lagged CEQQ is negative. }\end{array}$ \\
\hline$R O A$ & $\begin{array}{l}=\text { The ratio of operating income before depreciation (OIBDPQ) to lagged book } \\
\text { value of total assets (ATQ), expressed in percentage points. }\end{array}$ \\
\hline$\triangle S A L E S$ & $\begin{array}{l}=\text { Growth rate in sales (SALEQ) from the same quarter in the previous year to } \\
\text { the current quarter, expressed in percentage points. }\end{array}$ \\
\hline HIGH_GROWTH_FIRM & $\begin{array}{l}=\text { An indicator that equals one if a growth firm's market-to-book ratio in } 1992 \text { is } \\
\text { above the median of growth firms, and zero otherwise. }\end{array}$ \\
\hline LOW_GROWTH_FIRM & $\begin{aligned} &= \text { An indicator that equals one if a growth firm's market-to-book ratio in } 1992 \text { is } \\
& \text { below the median of growth firms, and zero otherwise. }\end{aligned}$ \\
\hline
\end{tabular}


Figure 1: Dynamic Test of the Investment Level

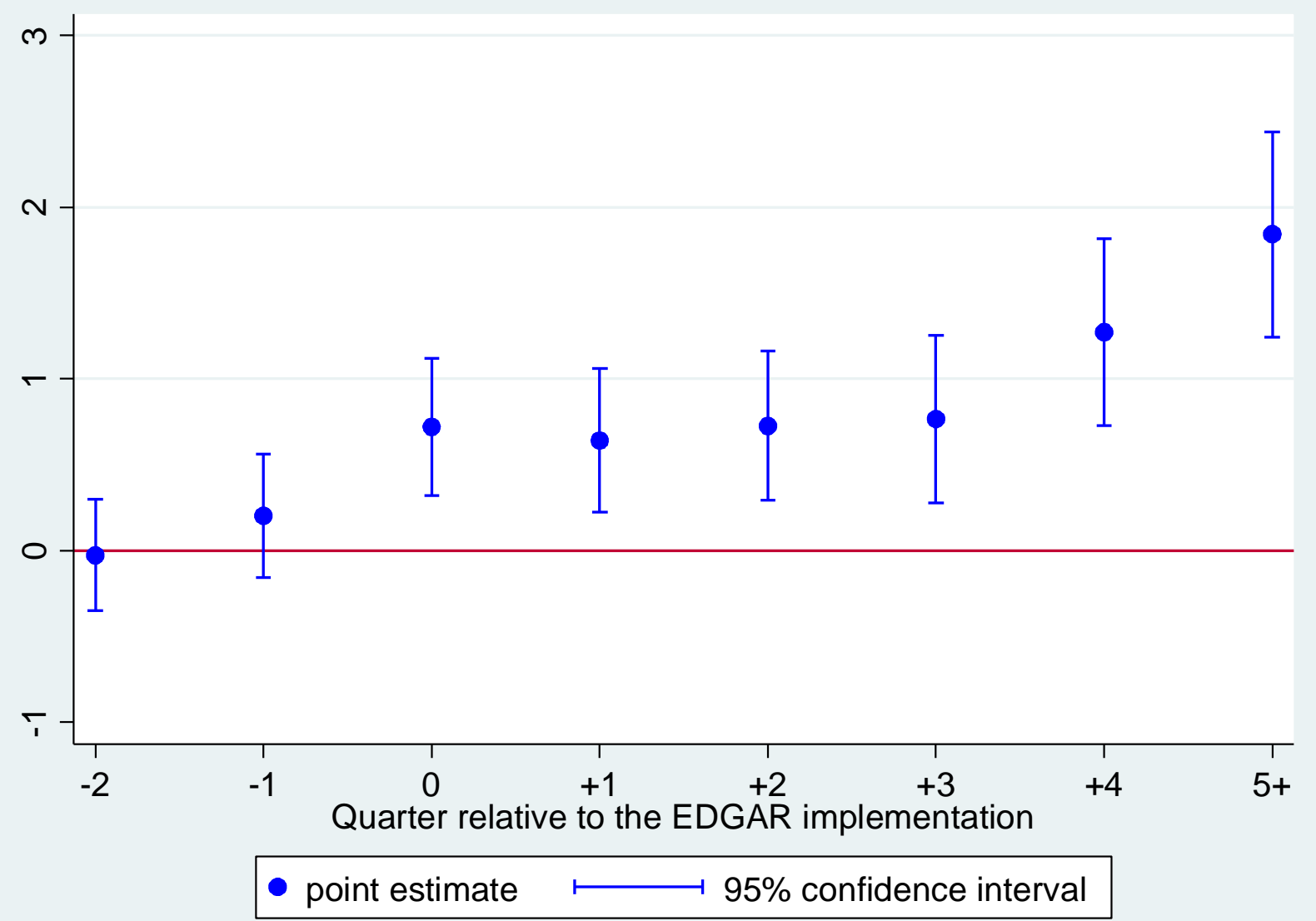

Notes: This figure reports the results from an event-time analysis of the effect of the EDGAR implementation on the level of corporate investment. Specifically, we re-estimate the regression model on the level of investment in column 1 of Table 2 by replacing EDGAR with a set of indicators for the quarters around the EDGAR implementation for each firm in our sample. Specifically, the regression model is as follows:

INVESTMENT

$$
\begin{aligned}
& =\alpha_{t}+\eta_{i}+\gamma_{1} \operatorname{EDGAR}(-2)_{i, t}+\gamma_{2} \operatorname{EDGAR}(-1)_{i, t}+\gamma_{3} \operatorname{EDGAR}(0)_{i, t}+\gamma_{4} \operatorname{EDGAR}(+1)_{i, t} \\
& +\gamma_{5} \operatorname{EDGAR}(+2)_{i, t}+\gamma_{6} \operatorname{EDGAR}(+3)_{i, t}+\gamma_{7} \operatorname{EDGAR}(+4)_{i, t}+\gamma_{8} \operatorname{EDGAR}(5+)_{i, t}+\varepsilon_{i, t}
\end{aligned}
$$

where $\operatorname{EDGAR}(-2)_{i, t}\left(\operatorname{EDGAR}(-1)_{i, t}\right)$ is an indicator that equals one if a firm will become a mandatory EDGAR filer in two quarters (one quarter), and zero otherwise. $\operatorname{EDGAR}(0)_{i, t}$ is an indicator that equals one if a firm becomes a mandatory EDGAR filer in the current quarter $t$, and zero otherwise. $E D G A R(+1)_{i, t}$ $\left(E D G A R(+2)_{i, t}, E D G A R(+3)_{i, t}, E D G A R(+4)_{i, t}\right)$ is an indicator that equals one if a firm became a mandatory EDGAR filer one quarter (two quarters, three quarters, four quarters) ago, and zero otherwise. $E D G A R(5+)_{i, t}$ is an indicator that equals one if a firm became a mandatory EDGAR filer five or more quarters ago, and zero otherwise. The figure reports the coefficient estimates on each event quarter indicator as well as their $95 \%$ confidence intervals. The estimation includes firm and year-quarter fixed effects. The standard errors are clustered at the firm level. 
Figure 2: Dynamic Test of the Investment-to-Price Sensitivity

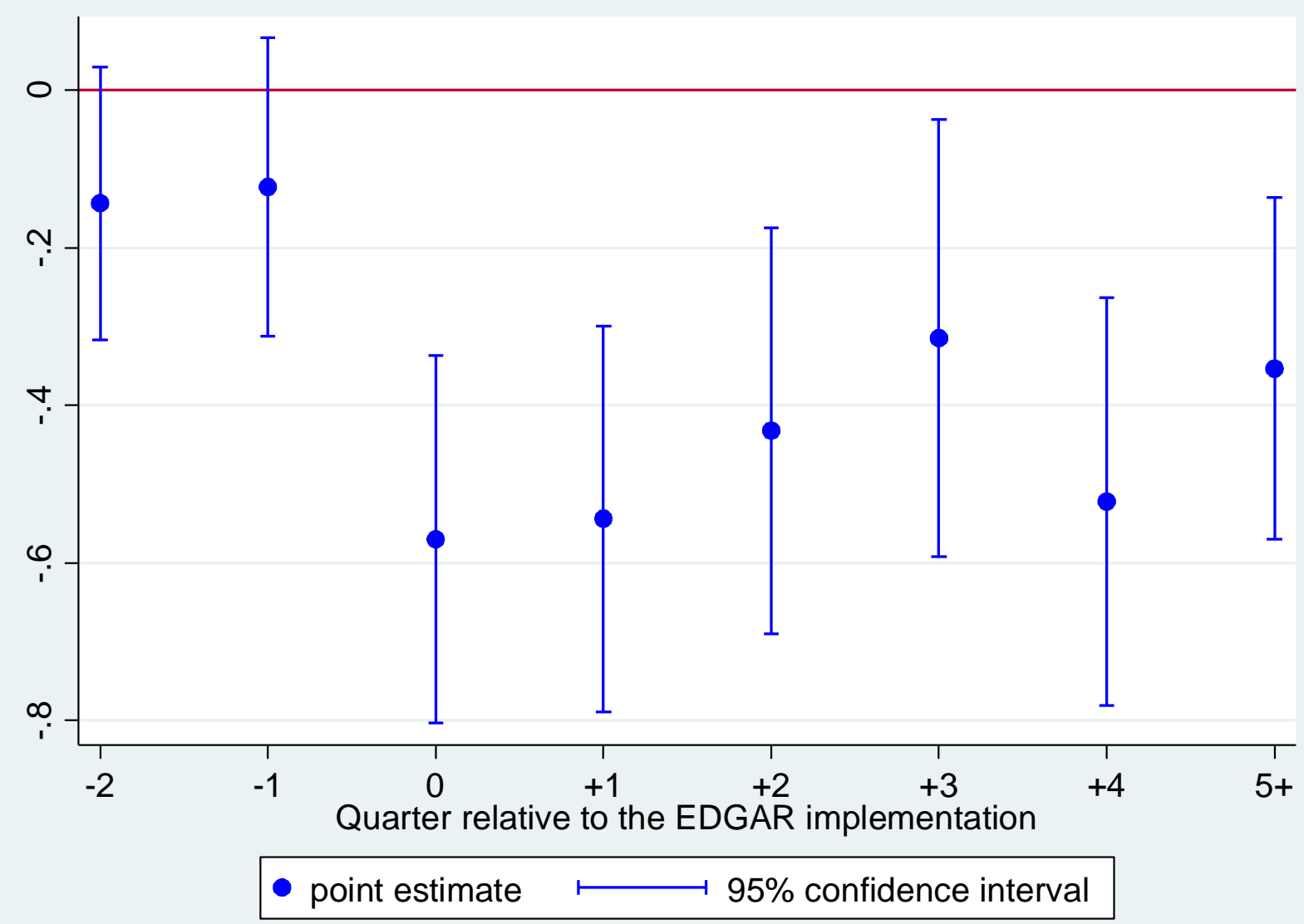

Notes: This figure reports the results from an event-time analysis of the effect of the EDGAR implementation on the investment-to-price sensitivity. Specifically, we re-estimate the regression model on the investment-toprice sensitivity in column 3 of Table 2 by replacing EDGAR with a set of indicators for the quarters around the EDGAR implementation for each firm in our sample. Specifically, the regression model is as follows:

$$
\begin{aligned}
& \text { INVESTMENT } T_{i, t+1} \\
& =\alpha_{t}+\eta_{i}+\gamma_{1} E D G A R_{i, t}+\gamma_{2} Q_{i, t}+\gamma_{3} C F_{i, t}+\gamma_{4} S_{I Z E_{i, t}}+\gamma_{5} Q_{i, t} \times E D G A R(-2)_{i, t} \\
& +\gamma_{6} Q_{i, t} \times E D G A R(-1)_{i, t}+\gamma_{7} Q_{i, t} \times E D G A R(0)_{i, t}+\gamma_{8} Q_{i, t} \times E D G A R(+1)_{i, t} \\
& +\gamma_{9} Q_{i, t} \times E D G A R(+2)_{i, t}+\gamma_{10} Q_{i, t} \times E D G A R(+3)_{i, t}+\gamma_{11} Q_{i, t} \times E D G A R(+4)_{i, t} \\
& +\gamma_{12} Q_{i, t} \times E D G A R(5+)_{i, t}+\gamma_{13} C F_{i, t} \times E D G A R_{i, t}+\gamma_{14} S I Z E_{i, t} \times E D G A R_{i, t}+\varepsilon_{i, t+1}
\end{aligned}
$$

where $\operatorname{EDGAR}(-2)_{i, t}\left(\operatorname{EDGAR}(-1)_{i, t}\right)$ is an indicator that equals one if a firm will become a mandatory EDGAR filer in two quarters (one quarter), and zero otherwise. $\operatorname{EDGAR}(0)_{i, t}$ is an indicator that equals one if a firm becomes a mandatory EDGAR filer in the current quarter $t$, and zero otherwise. $E D G A R(+1)_{i, t}$ $\left(\operatorname{EDGAR}(+2)_{i, t}, \operatorname{EDGAR}(+3)_{i, t}, \operatorname{EDGAR}(+4)_{i, t}\right)$ is an indicator that equals one if a firm became a mandatory EDGAR filer one quarter (two quarters, three quarters, four quarters) ago, and zero otherwise. $E D G A R(5+)_{i, t}$ is an indicator that equals one if a firm became a mandatory EDGAR filer five or more quarters ago, and zero otherwise. The figure reports the coefficient estimates on the interaction terms between $Q$ and each event quarter indicator as well as their $95 \%$ confidence intervals. The estimation includes firm and year-quarter fixed effects. The standard errors are clustered at the firm level. 
Figure 3: Path Diagram of Equity Financing

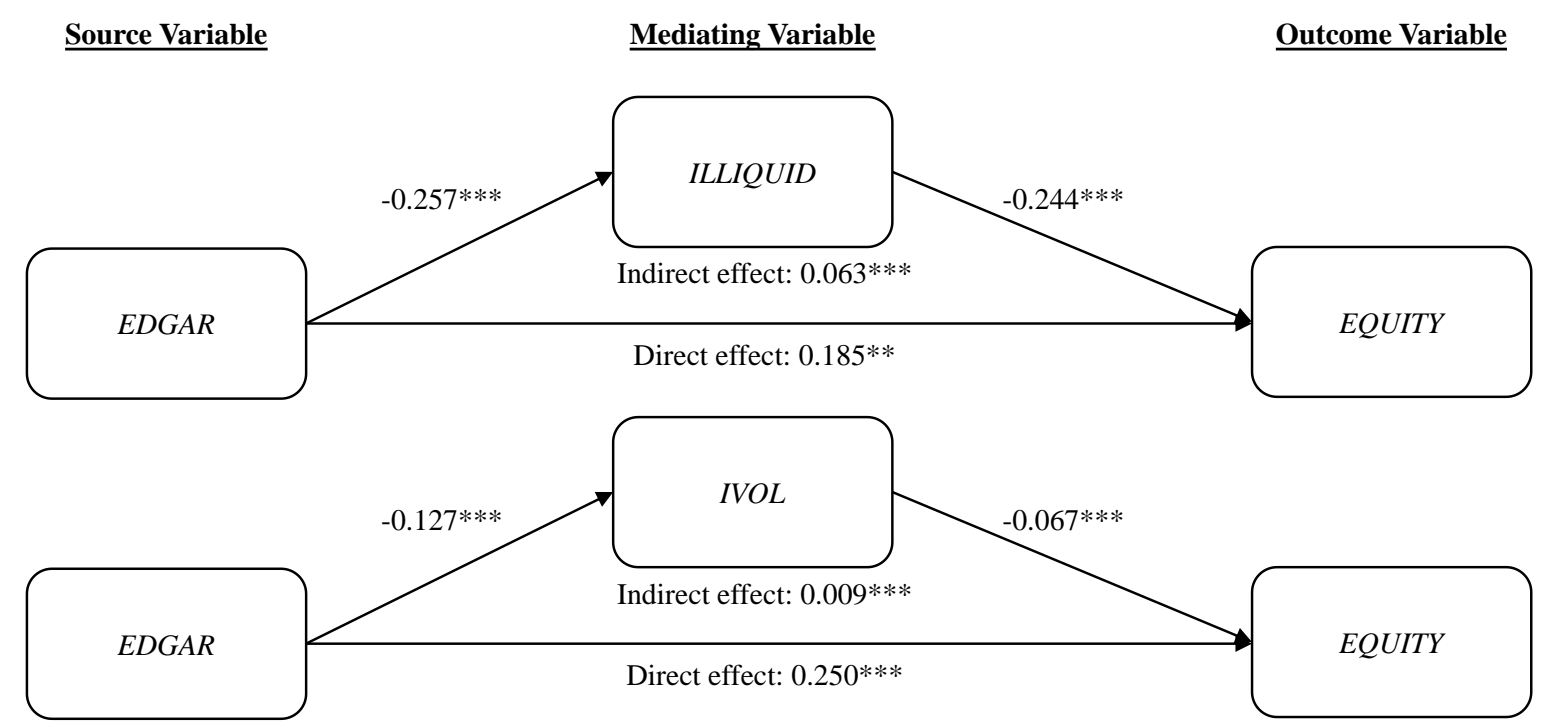

Notes: This figure plots the path diagram of equity financing. We estimate a structural equation model (SEM) of the direct effect of the EDGAR implementation on equity financing as well as the indirect effect of the EDGAR implementation on equity financing through ILLIQUID or IVOL. The path coefficients, indirect effect, and direct effect are obtained from the estimates in Panel B of Table 3. 
Figure 4: Path Diagram of Corporate Investment

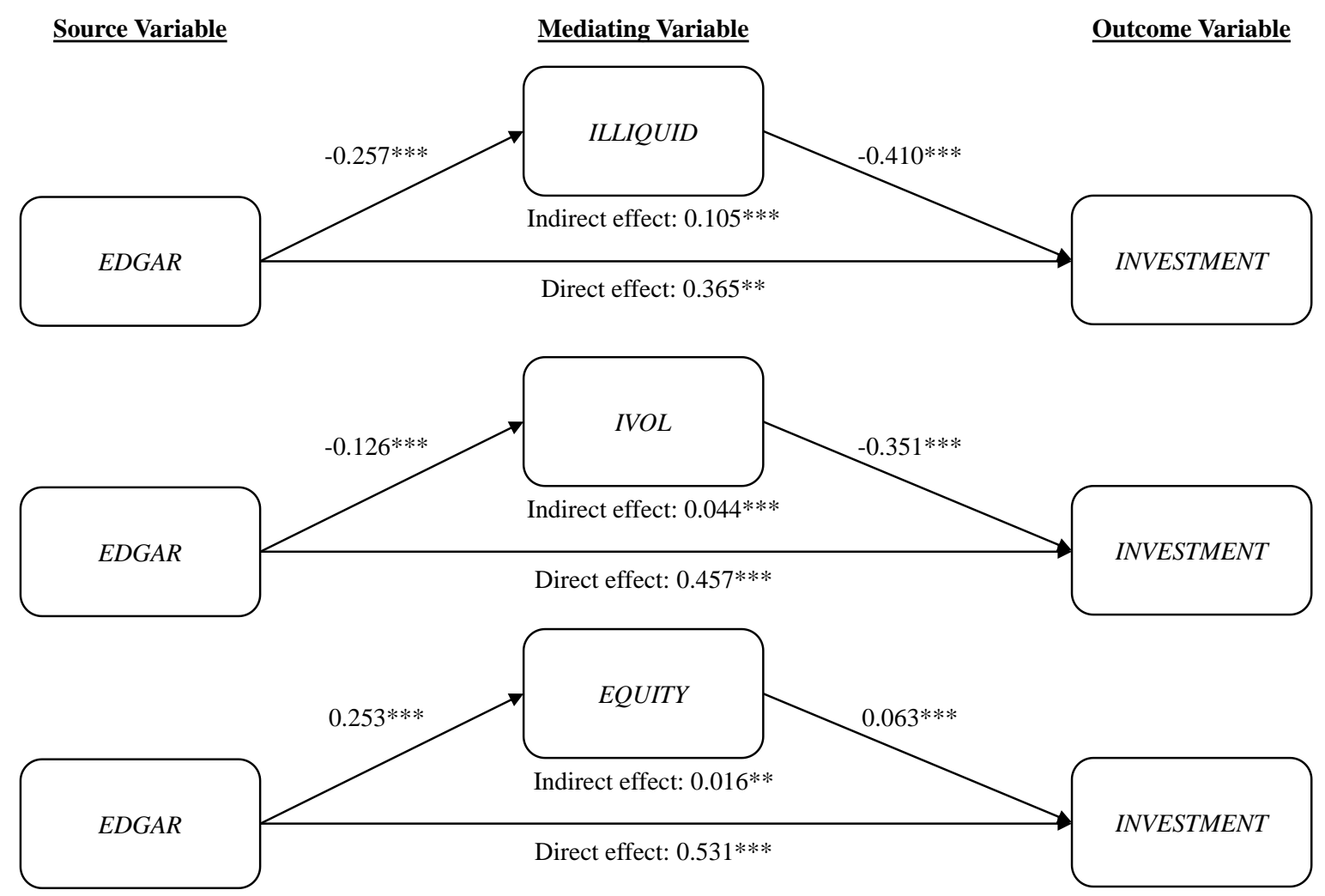

Notes: This figure plots the path diagram of corporate investment. We estimate a structural equation model (SEM) of the direct effect of the EDGAR implementation on corporate investment as well as the indirect effect of the EDGAR implementation on corporate investment through ILLIQUID, IVOL or EQUITY. The path coefficients, indirect effect, and direct effect are obtained from the estimates in Panel C of Table 3. 
Table 1: Descriptive Statistics

\begin{tabular}{|c|c|c|c|c|c|c|}
\hline \multicolumn{7}{|c|}{ Panel A: Summary Statistics } \\
\hline Variable & $\mathrm{N}$ & Mean & Std. Dev. & Q1 & Median & Q3 \\
\hline INVESTMENT & 66,628 & 7.090 & 7.582 & 2.543 & 4.867 & 8.768 \\
\hline$E D G A R$ & 66,628 & 0.494 & 0.500 & 0.000 & 0.000 & 1.000 \\
\hline$Q$ & 66,628 & 1.803 & 1.215 & 1.086 & 1.412 & 2.037 \\
\hline$C F$ & 66,628 & 1.708 & 4.394 & 0.966 & 2.374 & 3.759 \\
\hline SIZE & 66,628 & 5.106 & 1.760 & 3.770 & 4.861 & 6.241 \\
\hline PRC_INV & 66,628 & 0.222 & 0.477 & 0.041 & 0.081 & 0.186 \\
\hline ILLIQUID & 63,970 & 1.722 & 2.637 & 0.030 & 0.756 & 2.481 \\
\hline IVOL & 64,610 & 3.484 & 2.278 & 1.900 & 2.900 & 4.316 \\
\hline EQUITY & 64,335 & 1.001 & 5.058 & 0.000 & 0.012 & 0.183 \\
\hline GPIN & 12,283 & 25.066 & 18.164 & 13.842 & 20.510 & 29.987 \\
\hline$L A M B D A$ & 41,543 & 0.157 & 0.164 & 0.056 & 0.116 & 0.213 \\
\hline INSTOWN & 66,141 & 33.163 & 24.349 & 11.352 & 31.043 & 52.693 \\
\hline INSTOWN_TRA & 66,141 & 6.032 & 7.537 & 0.252 & 3.155 & 9.031 \\
\hline$R O E$ & 63,545 & 4.349 & 11.107 & 1.083 & 4.764 & 8.299 \\
\hline$R O A$ & 66,094 & 1.624 & 4.154 & 0.448 & 2.089 & 3.665 \\
\hline$\triangle S A L E S$ & 65,477 & 14.713 & 40.855 & -2.558 & 7.954 & 22.379 \\
\hline
\end{tabular}




\begin{tabular}{|c|c|c|c|c|c|c|c|c|c|c|c|c|c|c|c|c|c|}
\hline & & (AD & & (3) & & & & & & & & & & & & & \\
\hline (1) & INVESTMENT & & -0.0 & 0.28 & 0.07 & -0.10 & -0.11 & -0.11 & -0.03 & 0.12 & 0.01 & -0.03 & 007 & 0.18 & 0.02 & 0.08 & \\
\hline (2) & EDGAR & 0.01 & & 0.01 & 0.03 & 0.27 & -0.05 & -0 . & -0.1 & -0.04 & -0.01 & -0.14 & & 8 & 0.06 & 0.05 & -0.03 \\
\hline (3) & $Q$ & 0.33 & 0.05 & & -0.04 & -0.06 & -0.11 & -0.22 & -0.07 & 0.21 & 0.04 & -0.08 & 0.11 & 0.2 & -0.02 & 0.03 & 0.20 \\
\hline (4) & $C F$ & 0.24 & 0.04 & 0.33 & & 0.20 & -0.24 & -0.20 & -0.31 & -0.15 & 0.01 & -0.19 & 0.22 & 0.18 & 0.65 & 0.84 & 0.12 \\
\hline (5) & SIZE & 0.03 & 0.27 & 0.06 & 0.15 & & -0.33 & -0.50 & -0.54 & -0.09 & 0.08 & -0.38 & 0.62 & 0.38 & 0.27 & 0.26 & -0.03 \\
\hline (6) & PRC_INV & -0.24 & -0.18 & -0.41 & -0.40 & -0.68 & & 0.66 & 0.63 & -0.02 & 0.00 & 0.25 & -0.38 & -0.25 & -0.20 & -0.25 & -0.09 \\
\hline (7) & ILLIQUID & .17 & -0.23 & -0.34 & -0.24 & -0.64 & 0.70 & & 0.76 & -0.04 & 0.00 & 0.20 & -0.50 & -0.36 & -0.20 & -0.24 & -0.10 \\
\hline (8) & $I V O L$ & .06 & -0.22 & -0.16 & -0.28 & -0.64 & 0.74 & 0.65 & & 0.05 & 0.07 & 0.3 & -0. & -0. & -0 . & 33 & -0.04 \\
\hline (9) & EQUITY & & 0.05 & 0.42 & & 0.07 & -0.25 & -0.24 & -0.06 & & 0.00 & $\mathbf{0 . 0 3}$ & -0.00 & & -0.11 & -0.15 & 0.13 \\
\hline (10) & GPIN & .00 & -0.1 & -0.03 & -0 . & -0.01 & 0.07 & & 0.19 & 0.03 & & -0.04 & -0.03 & -0.02 & 0.02 & & -0.00 \\
\hline (11) & $\angle A M B D$ & & -0. & -0.10 & -0 . & -0. & 0.43 & & 0.35 & -0.05 & -0.06 & & -0.29 & -0 . & 16 & 21 & -0.02 \\
\hline (12) & INSTC & & 0.1 & 0.23 & & 0. & -0.65 & -0. & -0. & 0.2 & -0.08 & -0.26 & & 0.67 & 0. & & 0.05 \\
\hline (13) & INSTOWN_TRA & 0.26 & 0.1 & 0.34 & 0.2 & 0. & -0.59 & -0. & -0.38 & 0.3 & -0.01 & -0.23 & 0.77 & & 0.17 & 0.24 & 0.16 \\
\hline (14) & $R O E$ & 0.13 & 0.1 & 0.26 & 0.67 & 0.32 & -0.39 & -0.29 & -0.32 & 0.09 & -0.02 & -0.19 & 0.26 & 0.26 & & 0.78 & 0.11 \\
\hline (15) & $R O A$ & 0.22 & 0.0 & 0.36 & 0.8 & 0.24 & -0.46 & -0.3 & -0.3 & 0.1 & -0.04 & -0.1 & 0.3 & 0.3 & 0.87 & & 0.14 \\
\hline (16) & $\triangle S A L E S$ & 0.27 & -0.01 & 0.28 & 0.30 & 0.03 & -0.21 & -0.15 & -0.06 & 0.20 & 0.02 & -0.03 & 0.14 & 0.21 & 0.29 & 0.35 & \\
\hline
\end{tabular}

Notes: This table presents the descriptive statistics for the variables used in our main analysis. The sample period starts in the second quarter of 1991 and ends in the second quarter of 1998. Panel A presents the summary statistics for the sample, and Panel B presents the Pearson (above diagonal) and Spearman (below diagonal) correlations. All continuous variables are winsorized at the top and bottom one percent to mitigate the influence of extreme values. In Panel B, numbers in bold are significant at the 1\% level (two-tailed). Variable definitions are provided in Appendix C. 
Table 2: Main Results on Corporate Investment

\begin{tabular}{|c|c|c|c|}
\hline \multirow[t]{2}{*}{ Dependent Variable $=$} & \multicolumn{3}{|c|}{ INVESTMENT } \\
\hline & (1) & $(2)$ & (3) \\
\hline EDGAR & $\begin{array}{c}0.613 * * * \\
(4.05)\end{array}$ & $\begin{array}{c}0.403 * * * \\
(2.84)\end{array}$ & $\begin{array}{c}0.933 * * * \\
(3.09)\end{array}$ \\
\hline$Q$ & & $\begin{array}{c}1.714 * * * \\
(18.97)\end{array}$ & $\begin{array}{c}1.908 * * * \\
(18.64)\end{array}$ \\
\hline$C F$ & & $\begin{array}{c}0.178 * * * \\
(12.94)\end{array}$ & $\begin{array}{c}0.136^{* * * *} \\
(7.34)\end{array}$ \\
\hline SIZE & & $\begin{array}{c}0.354 * * \\
(2.10)\end{array}$ & $\begin{array}{c}0.381 * * \\
(2.23)\end{array}$ \\
\hline$Q \times E D G A R$ & & & $\begin{array}{c}-0.392 * * * * \\
(-3.90)\end{array}$ \\
\hline$C F \times E D G A R$ & & & $\begin{array}{c}0.081 * * * \\
(3.35)\end{array}$ \\
\hline$S I Z E \times E D G A R$ & & & $\begin{array}{l}0.004 \\
(0.08)\end{array}$ \\
\hline Firm FE & Yes & Yes & Yes \\
\hline Year-Quarter FE & Yes & Yes & Yes \\
\hline Observations & 66,628 & 66,628 & 66,628 \\
\hline Adjusted $R$-squared & 0.272 & 0.302 & 0.304 \\
\hline
\end{tabular}

Notes: This table reports the regression results on corporate investment. The dependent variable is the quarterly investment made by the firm (INVESTMENT), defined as capital expenditure in the next quarter scaled by the net property, plant, and equipment at the current quarter end. EDGAR is an indicator that equals one after a firm becomes a mandatory EDGAR filer, and zero otherwise. $Q$ is Tobin's Q. All other variables are defined in Appendix C. The $t$-statistics of robust standard errors clustered at the firm level are reported in parentheses. ***, $* *$, and $*$ indicate significance at the $1 \%, 5 \%$, and $10 \%$ levels, respectively. 
Table 3: Equity Financing Channel

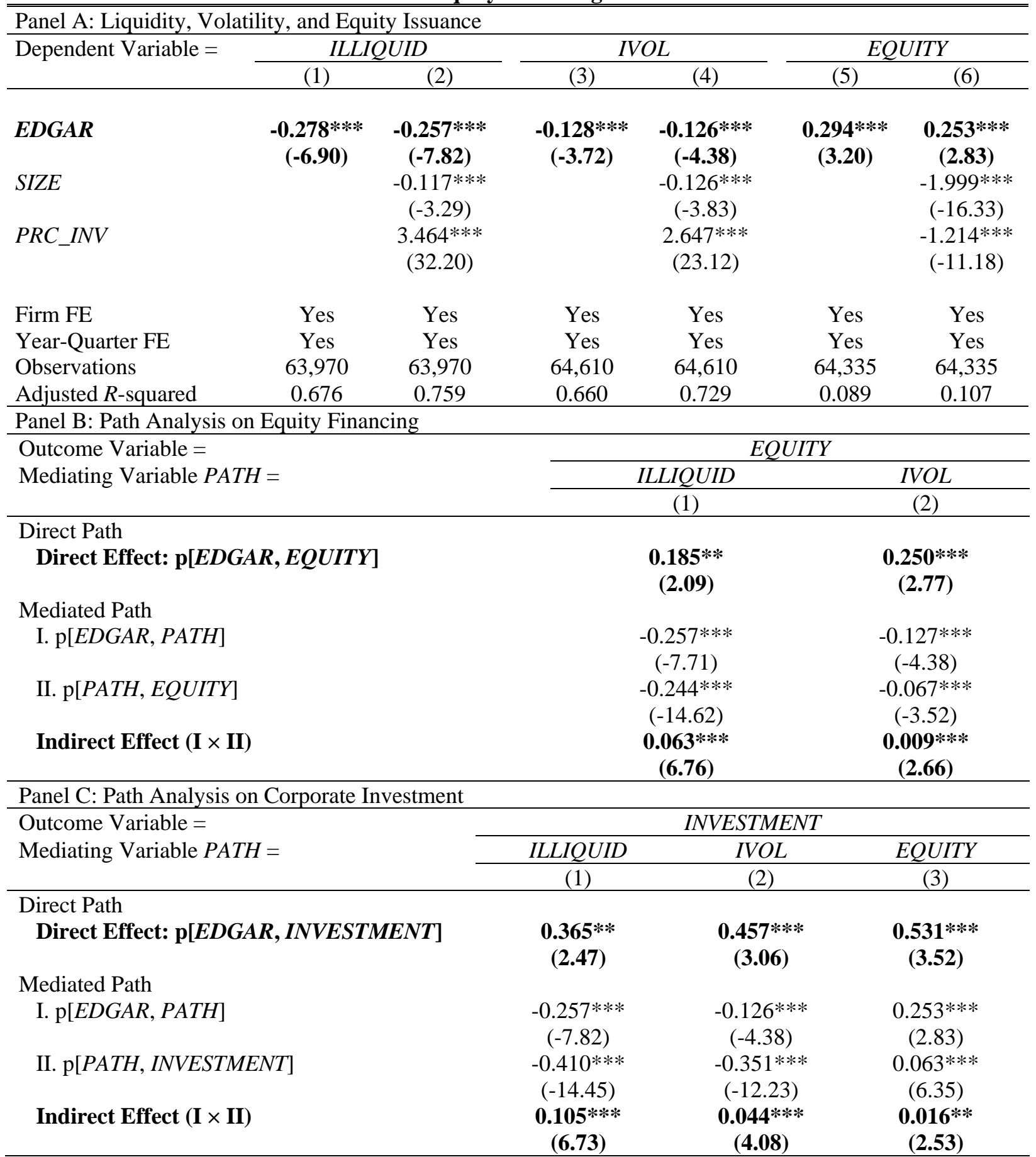

Notes: This table reports the regression results on the equity financing channel. In Panel A, the dependent variables include the high-low spread estimator (ILLIQUID), idiosyncratic return volatility (IVOL), and the amount of equity issuance (EQUITY). EDGAR is an indicator that equals one after a firm becomes a mandatory EDGAR filer, and zero otherwise. All other variables are defined in Appendix C. The $t$-statistics of robust standard errors clustered at the firm level are reported in parentheses. Panel B presents the results of the path analysis on equity financing. We estimate a structural equation model (SEM) of the direct effect of the EDGAR implementation on equity financing as well as the indirect effect of the EDGAR implementation on equity financing through ILLIQUID or IVOL. Panel C presents the results of the path analysis on corporate investment. 
We estimate a structural equation model (SEM) of the direct effect of the EDGAR implementation on corporate investment as well as the indirect effect of the EDGAR implementation on corporate investment through ILLIQUID, IVOL or EQUITY. In Panels B and C, the path coefficient is labeled p[.]; control variables, firm fixed effects, and year-quarter fixed effects are included in each of the SEM equations; the $z$-statistics of robust standard errors clustered at the firm level are reported in parentheses. $*, * *$, and $* * *$ denote significance at the $10 \%, 5 \%$, and $1 \%$ levels, respectively. 
Table 4: Managerial Learning Channel

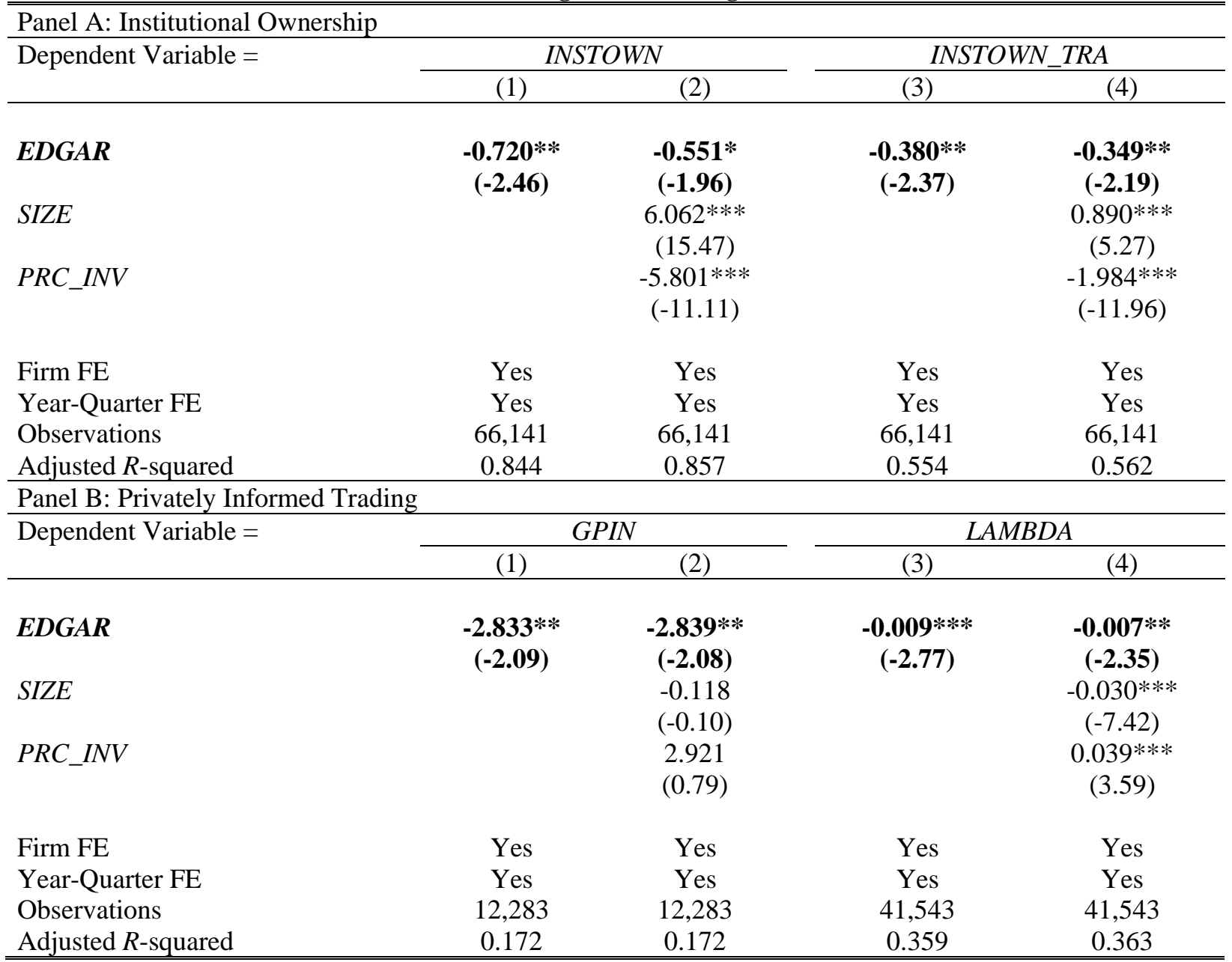

Notes: This table reports the regression results on the managerial learning channel. In Panel A, the dependent variables include total institutional ownership (INSTOWN) and transient institutional ownership (INSTOWN_TRA). In Panel B, the dependent variables include the probability of informed trading $(G P I N)$ and the adverse selection component of the bid-ask spread (LAMBDA). EDGAR is an indicator that equals one after a firm becomes a mandatory EDGAR filer, and zero otherwise. All other variables are defined in Appendix C. The $t$-statistics of robust standard errors clustered at the firm level are reported in parentheses. ***,**, and * indicate significance at the $1 \%, 5 \%$, and $10 \%$ levels, respectively. 
Table 5: Growth Firms versus Value Firms

Panel A: Managerial Learning Channel

Dependent Variable $=$ INSTOWN INSTOWN_TRA GPIN LAMBDA

\begin{tabular}{|c|c|c|c|c|}
\hline & (1) & (2) & (3) & (4) \\
\hline EDGAR $\times$ GROWTH_FIRM (a) & $\begin{array}{c}-0.942 * * * \\
(-2.73)\end{array}$ & $\begin{array}{c}-0.824 * * * \\
(-4.23)\end{array}$ & $\begin{array}{c}-4.206 * * \\
(-2.45)\end{array}$ & $\begin{array}{c}-0.018 * * * * \\
(-4.62)\end{array}$ \\
\hline$E D G A R \times V A L U E \_F I R M(b)$ & $\begin{array}{l}-0.196 \\
(-0.52)\end{array}$ & $\begin{array}{l}-\mathbf{0 . 0 5 5} \\
(-0.29)\end{array}$ & $\begin{array}{l}-1.725 \\
(-1.25)\end{array}$ & $\begin{array}{l}-0.000 \\
(-0.09)\end{array}$ \\
\hline Test of $(a)=(b)(p$-value $)$ & 0.056 & $<0.001$ & 0.048 & $<0.001$ \\
\hline $\begin{array}{l}\text { Firm FE } \\
\text { Year-Quarter FE } \\
\text { Observations } \\
\text { Adjusted } R \text {-squared } \\
\end{array}$ & $\begin{array}{c}\text { Yes } \\
\text { Yes } \\
62,096 \\
0.851 \\
\end{array}$ & $\begin{array}{c}\text { Yes } \\
\text { Yes } \\
62,096 \\
0.558\end{array}$ & $\begin{array}{c}\text { Yes } \\
\text { Yes } \\
12,112 \\
0.173\end{array}$ & $\begin{array}{c}\text { Yes } \\
\text { Yes } \\
39,124 \\
0.357\end{array}$ \\
\hline \multicolumn{5}{|l|}{ Panel B: Investment-to-Price Sensitivity } \\
\hline \multirow[t]{2}{*}{ Dependent Variable $=$} & & \multicolumn{3}{|c|}{ INVESTMENT } \\
\hline & & $(1)$ & & (2) \\
\hline$E D G A R$ & & $\begin{array}{c}0.814 * * * \\
(2.67)\end{array}$ & & $\begin{array}{l}0.334 \\
(1.00)\end{array}$ \\
\hline$Q$ & & $\begin{array}{c}1.915^{* * * *} \\
(18.08)\end{array}$ & & $\begin{array}{c}1.807 * * * \\
(16.38)\end{array}$ \\
\hline$C F$ & & $\begin{array}{c}0.135^{* * * *} \\
(6.81)\end{array}$ & & $\begin{array}{c}0.134 * * * \\
(6.74)\end{array}$ \\
\hline SIZE & & $\begin{array}{c}0.393 * * \\
(2.17)\end{array}$ & & $\begin{array}{c}0.388^{* *} \\
(2.14)\end{array}$ \\
\hline$Q \times E D G A R$ & & $\begin{array}{c}-\mathbf{0 . 3 4 2} * * * * \\
(-3.30)\end{array}$ & & \\
\hline$Q \times E D G A R \times G R O W T H \_F I R M(a)$ & & & & $\begin{array}{c}-0.291 * * * * \\
(-2.74)\end{array}$ \\
\hline$Q \times E D G A R \times V A L U E \_F I R M(b)$ & & & & $\begin{array}{l}\mathbf{0 . 1 5 3} \\
(\mathbf{0 . 7 9})\end{array}$ \\
\hline$C F \times E D G A R$ & & $\begin{array}{c}0.080 * * * \\
(3.13)\end{array}$ & & $\begin{array}{c}0.077 * * * \\
(2.99)\end{array}$ \\
\hline$S I Z E \times E D G A R$ & & $\begin{array}{l}0.008 \\
(0.18)\end{array}$ & & $\begin{array}{l}0.035 \\
(0.74)\end{array}$ \\
\hline Test of $(a)=(b)(p$-value $)$ & & & & $<0.001$ \\
\hline Firm FE & & Yes & & Yes \\
\hline Year-Quarter FE & & Yes & & Yes \\
\hline Observations & & 62,441 & & 62,441 \\
\hline Adjusted $R$-squared & & 0.304 & & 0.304 \\
\hline
\end{tabular}




\begin{tabular}{|c|c|c|c|c|}
\hline \\
\hline & \multicolumn{4}{|c|}{$\begin{array}{ll}\text { Panel C: Equity Financing Channel } & \\
\text { Dependent Variable }= & \text { ILLIOUID }\end{array}$} \\
\hline & \begin{tabular}{cc} 
Dependent Variable $=$ & $(1)$ \\
\cline { 2 - 2 }
\end{tabular} & $\begin{array}{c}I V O L \\
(2) \\
\end{array}$ & (3) & (4) \\
\hline$E D G A R \times G R O W T H \_F I R M(\mathbf{a})$ & $\begin{array}{l}-0.071 \\
(-1.43)\end{array}$ & $\begin{array}{l}-\mathbf{0 . 0 2 8} \\
(-0.70)\end{array}$ & $\begin{array}{c}\mathbf{0 . 0 5 2} \\
(\mathbf{0 . 4 8})\end{array}$ & $\begin{array}{l}-0.123 \\
(-0.68)\end{array}$ \\
\hline$E D G A R \times V A L U E \_F I R M(b)$ & $\begin{array}{c}-0.436 * * * * \\
(-8.42)\end{array}$ & $\begin{array}{c}-0.185 * * * \\
(-4.18)\end{array}$ & $\begin{array}{c}0.490 * * * \\
(4.79)\end{array}$ & $\begin{array}{c}1.384 * * * \\
(7.74)\end{array}$ \\
\hline Test of $(a)=(b)(p$-value $)$ & $<0.001$ & $<0.001$ & $<0.001$ & $<0.001$ \\
\hline Firm FE & Yes & Yes & Yes & Yes \\
\hline Year-Quarter FE & Yes & Yes & Yes & Yes \\
\hline Observations & 60,438 & 61,059 & 60,335 & 62,441 \\
\hline Adjusted $R$-squared & 0.681 & 0.665 & 0.090 & 0.273 \\
\hline
\end{tabular}

Notes: This table reports the regression results for the differential treatment effects in growth firms and value firms. In Panel A, the dependent variables include total institutional ownership (INSTOWN), transient institutional ownership (INSTOWN_TRA), the probability of informed trading (GPIN), and the adverse selection component of the bid-ask spread ( $L A M B D A)$. In Panel $\mathrm{B}$, the dependent variable is the quarterly investment made by the firm (INVESTMENT), defined as capital expenditure in the next quarter scaled by the net property, plant, and equipment at the current quarter end. In Panel C, the dependent variables include the high-low spread estimator (ILLIQUID), idiosyncratic return volatility (IVOL), the amount of equity issuance (EQUITY), and the quarterly investment made by the firm (INVESTMENT). GROWTH_FIRM (VALUE_FIRM) is an indicator that equals one if a firm's market-to-book ratio in 1992 is above (below) the median, and zero otherwise. EDGAR is an indicator that equals one after a firm becomes a mandatory EDGAR filer, and zero otherwise. All other variables are defined in Appendix C. Reflecting the signed nature of the predictions, the test for equal treatment effects is one-sided. The $t$-statistics of robust standard errors clustered at the firm level are reported in parentheses. $* * *, * *$, and $*$ indicate significance at the $1 \%, 5 \%$, and $10 \%$ levels, respectively. 
Table 6: Firm Performance

\begin{tabular}{|c|c|c|c|c|c|c|c|}
\hline \multicolumn{8}{|c|}{ Panel A: Baseline Analyses } \\
\hline \multirow[t]{2}{*}{ Dependent Variable $=$} & \multicolumn{2}{|c|}{$R O E$} & \multicolumn{3}{|c|}{$R O A$} & \multicolumn{2}{|c|}{$\triangle S A L E S$} \\
\hline & $(1)$ & $(2)$ & (3) & \multicolumn{2}{|c|}{$(4)$} & $(5)$ & $(6)$ \\
\hline EDGAR & \multirow[t]{3}{*}{$\begin{array}{c}0.388^{* * *} \\
(1.97)\end{array}$} & \multirow{2}{*}{$\begin{array}{c}\mathbf{0 . 4 0 3} * * \\
(\mathbf{2 . 0 5}) \\
0.168 \\
(0.57)\end{array}$} & \multirow{2}{*}{\multicolumn{2}{|c|}{$\begin{array}{c}\mathbf{0 . 1 9 8} * * * \\
(\mathbf{3 . 0 7})\end{array}$}} & & $\begin{array}{c}2.878 * * * \\
(2.89)\end{array}$ & $\begin{array}{c}2.989 * * * \\
(3.01)\end{array}$ \\
\hline SIZE & & & & & $\begin{array}{l}-0.054 \\
(-0.61)\end{array}$ & & $2.220^{*}$ \\
\hline PRC_INV & & $\begin{array}{c}-2.430 * * * \\
(-5.21)\end{array}$ & & \multicolumn{2}{|c|}{$\begin{array}{c}-0.853 * * * \\
(-8.79)\end{array}$} & & $\begin{array}{c}-9.984 * * * \\
(-8.35)\end{array}$ \\
\hline Firm FE & Yes & Yes & \multicolumn{2}{|c|}{ Yes } & Yes & Yes & Yes \\
\hline Year-Quarter FE & Yes & Yes & \multicolumn{2}{|c|}{ Yes } & Yes & Yes & Yes \\
\hline Observations & 63,545 & 63,545 & 66,094 & \multicolumn{2}{|c|}{66,094} & 65,477 & 65,477 \\
\hline Adjusted $R$-squared & 0.446 & 0.449 & 0.55 & \multicolumn{2}{|c|}{0.560} & 0.179 & 0.184 \\
\hline \multicolumn{8}{|c|}{ Panel B: Growth Firms versus Value Firms } \\
\hline Dependent Variable $=$ & & $R O E$ & & $R O A$ & & $\triangle S A$ & $L E S$ \\
\hline & & $(1)$ & $(2)$ & (3) & $(4)$ & $(5)$ & $(6)$ \\
\hline$E D G A R \times G R O W T H \_F$ & (a) & $\begin{array}{l}-0.357 \\
(-1.40)\end{array}$ & $\begin{array}{l}-0.341 \\
(-1.34)\end{array}$ & $\begin{array}{l}-0.111 \\
(-1.34)\end{array}$ & $\begin{array}{l}-0.092 \\
(-1.11)\end{array}$ & $\begin{array}{l}-\mathbf{- 0 . 1 7 2} \\
\mathbf{( - 0 . 1 5 )}\end{array}$ & $\begin{array}{l}-\mathbf{- 0 . 1 3 6} \\
(-\mathbf{0 . 1 2})\end{array}$ \\
\hline$E D G A R \times V A L U E \_F I K$ & & $\begin{array}{c}1.067 * * * * \\
(4.56)\end{array}$ & $\begin{array}{c}1.073 * * * * \\
(4.55)\end{array}$ & $\begin{array}{c}0.515 * * * \\
(6.23)\end{array}$ & $\begin{array}{c}0.509 * * * \\
(6.18)\end{array}$ & $\begin{array}{c}\mathbf{6 . 6 5 0} * * * \\
(\mathbf{5 . 5 2})\end{array}$ & $\begin{array}{c}6.853 * * * * \\
(5.66)\end{array}$ \\
\hline Test of $(\mathbf{a})=(\mathbf{b})(p$-valu & & $<0.001$ & $<0.001$ & $<0.001$ & $<0.001$ & $<0.001$ & $<0.001$ \\
\hline Controls & & No & Yes & No & Yes & No & Yes \\
\hline Firm FE & & Yes & Yes & Yes & Yes & Yes & Yes \\
\hline Year-Quarter FE & & Yes & Yes & Yes & Yes & Yes & Yes \\
\hline Observations & & 61,065 & 61,065 & 62,054 & 62,054 & 61,461 & 61,461 \\
\hline Adjusted $R$-squared & & 0.443 & 0.446 & 0.562 & 0.565 & 0.177 & 0.182 \\
\hline Panel C: High versus Lc & rowth Firm & & & & & & \\
\hline Dependent Variable $=$ & & & $O E$ & & $O A$ & $\Delta S A$ & $4 L E S$ \\
\hline & & $(1)$ & $(2)$ & (3) & $(4)$ & $(5)$ & $(6)$ \\
\hline$E D G A R \times H I G H \_G R O$ & IFIRM (a) & $\begin{array}{c}-1.018 * * * * \\
(-2.66)\end{array}$ & $\begin{array}{c}-0.974 * * \\
(-2.53)\end{array}$ & $\begin{array}{c}-0.290 * * \\
(-2.29)\end{array}$ & $\begin{array}{c}-0.257 * * \\
(-2.03)\end{array}$ & $\begin{array}{l}-2.617^{*} \\
(-1.75)\end{array}$ & $\begin{array}{c}-2.560 * \\
(-1.73)\end{array}$ \\
\hline EDGAR $\times L O W \_G R O W$ & $F I R M(b)$ & $\begin{array}{l}0.295 \\
(0.95)\end{array}$ & $\begin{array}{l}0.276 \\
(0.90)\end{array}$ & $\begin{array}{l}\mathbf{0 . 0 6 9} \\
(\mathbf{0 . 6 8})\end{array}$ & $\begin{array}{l}\mathbf{0 . 0 7 1} \\
(\mathbf{0 . 7 1})\end{array}$ & $\begin{array}{c}2.271^{*} \\
(1.69)\end{array}$ & $\begin{array}{c}2.254 * \\
(1.69)\end{array}$ \\
\hline$E D G A R \times V A L U E \_F I R N$ & & $\begin{array}{c}1.071 * * * \\
(4.57)\end{array}$ & $\begin{array}{c}1.082 * * * \\
(4.58)\end{array}$ & $\begin{array}{c}0.516^{* * *} \\
(6.23)\end{array}$ & $\begin{array}{c}0.511 * * * \\
(6.20)\end{array}$ & $\begin{array}{c}6.668 * * * \\
(5.53)\end{array}$ & $\begin{array}{c}6.892 * * * \\
(5.68)\end{array}$ \\
\hline Test of $(a)=(b)(p$-valu & & 0.006 & 0.008 & 0.023 & 0.036 & 0.003 & 0.003 \\
\hline Controls & & No & Yes & No & Yes & No & Yes \\
\hline Firm FE & & Yes & Yes & Yes & Yes & Yes & Yes \\
\hline Year-Quarter FE & & Yes & Yes & Yes & Yes & Yes & Yes \\
\hline Observations & & 61,065 & 61,065 & 62,054 & 62,054 & 61,461 & 61,461 \\
\hline Adjusted $R$-squared & & 0.443 & 0.446 & 0.562 & 0.565 & 0.177 & 0.182 \\
\hline
\end{tabular}

Notes: This table reports the regression results on firm performance. The dependent variables include the return on equity $(R O E)$, return on assets $(R O A)$, and sales growth $(\triangle S A L E S)$. EDGAR is an indicator that equals one 
after a firm becomes a mandatory EDGAR filer, and zero otherwise. GROWTH_FIRM (VALUE_FIRM) is an indicator that equals one if a firm's market-to-book ratio in 1992 is above (below) the median, and zero otherwise. HIGH_GROWTH_FIRM (LOW_GROWTH_FIRM) is an indicator that equals one if a growth firm's market-tobook ratio in 1992 is above (below) the median of growth firms, and zero otherwise. All other variables are defined in Appendix C. The $t$-statistics of robust standard errors clustered at the firm level are reported in parentheses. $* * *, * *$, and $*$ indicate significance at the $1 \%, 5 \%$, and $10 \%$ levels, respectively. 
Table 7: Removal of Transitional Filers

\begin{tabular}{|c|c|c|c|}
\hline \multirow[t]{2}{*}{ Dependent Variable $=$} & \multicolumn{3}{|c|}{ INVESTMENT } \\
\hline & $(1)$ & $(2)$ & (3) \\
\hline EDGAR & $\begin{array}{c}0.717 * * * \\
(4.60)\end{array}$ & $\begin{array}{c}\text { 0.488**** } \\
(3.32)\end{array}$ & $\begin{array}{c}1.073 * * * \\
(3.37)\end{array}$ \\
\hline$Q$ & & $\begin{array}{c}1.711 * * * \\
(18.77)\end{array}$ & $\begin{array}{c}1.903 * * * \\
(18.50)\end{array}$ \\
\hline$C F$ & & $\begin{array}{c}0.178 * * * \\
(12.81)\end{array}$ & $\begin{array}{c}0.136^{* * * *} \\
(7.29)\end{array}$ \\
\hline SIZE & & $\begin{array}{c}0.353 * * \\
(2.07)\end{array}$ & $\begin{array}{c}0.386^{* *} \\
(2.21)\end{array}$ \\
\hline$Q \times E D G A R$ & & & $\begin{array}{c}-0.388 * * * \\
(-3.82)\end{array}$ \\
\hline$C F \times E D G A R$ & & & $\begin{array}{c}0.082 * * * \\
(3.38)\end{array}$ \\
\hline$S I Z E \times E D G A R$ & & & $\begin{array}{l}-0.008 \\
(-0.16)\end{array}$ \\
\hline Firm FE & Yes & Yes & Yes \\
\hline Year-Quarter FE & Yes & Yes & Yes \\
\hline Observations & 64,612 & 64,612 & 64,612 \\
\hline Adjusted $R$-squared & 0.271 & 0.301 & 0.302 \\
\hline
\end{tabular}

Notes: This table reports the regression results on corporate investment after excluding firms assigned to Group CF-01 as this group contains "transitional" filers that volunteered to file electronically prior to the mandatory phase-in of the EDGAR system in April 1993. The dependent variable is the quarterly investment made by the firm (INVESTMENT), defined as capital expenditure in the next quarter scaled by the net property, plant, and equipment at the current quarter end. EDGAR is an indicator that equals one after a firm becomes a mandatory EDGAR filer, and zero otherwise. $Q$ is Tobin's Q. All other variables are defined in Appendix C. The $t$-statistics of robust standard errors clustered at the firm level are reported in parentheses. ***, **, and * indicate significance at the $1 \%, 5 \%$, and $10 \%$ levels, respectively. 
Table 8: Requirement of Free Online Access

\begin{tabular}{|c|c|c|c|}
\hline \multirow[t]{2}{*}{ Dependent Variable $=$} & \multicolumn{3}{|c|}{ INVESTMENT } \\
\hline & (1) & (2) & (3) \\
\hline EDGAR & $\begin{array}{c}0.803 * * * \\
(4.84)\end{array}$ & $\begin{array}{c}0.532 * * * * \\
(3.39)\end{array}$ & $\begin{array}{c}1.017 * * * \\
(3.40)\end{array}$ \\
\hline$Q$ & & $\begin{array}{c}1.712 * * * \\
(18.95)\end{array}$ & $\begin{array}{c}1.900 * * * \\
(18.64)\end{array}$ \\
\hline$C F$ & & $\begin{array}{c}0.177 * * * \\
(12.93)\end{array}$ & $\begin{array}{c}0.134 * * * \\
(7.33)\end{array}$ \\
\hline SIZE & & $\begin{array}{c}0.356^{* *} \\
(2.12)\end{array}$ & $\begin{array}{c}0.375 * * \\
(2.19)\end{array}$ \\
\hline$Q \times E D G A R$ & & & $\begin{array}{c}-0.383 * * * \\
(-3.85)\end{array}$ \\
\hline$C F \times E D G A R$ & & & $\begin{array}{c}0.087 * * * * \\
(3.59)\end{array}$ \\
\hline$S I Z E \times E D G A R$ & & & $\begin{array}{l}0.006 \\
(0.14)\end{array}$ \\
\hline Firm FE & Yes & Yes & Yes \\
\hline Year-Quarter FE & Yes & Yes & Yes \\
\hline Observations & 66,628 & 66,628 & 66,628 \\
\hline Adjusted $R$-squared & 0.272 & 0.302 & 0.304 \\
\hline
\end{tabular}

Notes: This table reports the regression results on corporate investment after redefining the EDGAR indicator for the first four groups to take the value of one if the firm-quarter is after January 17, 1994 (when all electronic EDGAR filings became freely available online via a National Science Foundation grant to New York University) and zero otherwise. EDGAR for the remaining six groups is an indicator that equals one after a firm becomes a mandatory EDGAR filer, and zero otherwise. The dependent variable is the quarterly investment made by the firm (INVESTMENT), defined as capital expenditure in the next quarter scaled by the net property, plant, and equipment at the current quarter end. $Q$ is Tobin's Q. All other variables are defined in Appendix C. The $t$ statistics of robust standard errors clustered at the firm level are reported in parentheses. $* * *, * *$, and $*$ indicate significance at the $1 \%, 5 \%$, and $10 \%$ levels, respectively. 


\title{
Online Appendix for
}

\section{The Real Effects of Modern Information Technologies}

\author{
Itay Goldstein ${ }^{\mathrm{a}}$, Shijie Yang ${ }^{\mathrm{b}}$, Luo Zuo ${ }^{\mathrm{c}}$ \\ ${ }^{a}$ Wharton School, University of Pennsylvania \\ ${ }^{\mathrm{b}}$ School of Management and Economics, Chinese University of Hong Kong, Shenzhen \\ ${ }^{c}$ Samuel Curtis Johnson Graduate School of Management, Cornell University
}


Table A1: An Alternative Proxy for Firm Size

\begin{tabular}{|c|c|c|c|}
\hline \multirow[t]{2}{*}{ Dependent Variable $=$} & \multicolumn{3}{|c|}{ INVESTMENT } \\
\hline & (1) & $(2)$ & (3) \\
\hline$E D G A R$ & $\begin{array}{c}0.613 * * * \\
(4.05)\end{array}$ & $\begin{array}{c}0.406 * * * \\
(2.90)\end{array}$ & $\begin{array}{c}1.520 * * * \\
(6.14)\end{array}$ \\
\hline$Q$ & & $\begin{array}{c}1.118^{* * *} \\
(10.59)\end{array}$ & $\begin{array}{c}1.305^{* * *} \\
(11.27)\end{array}$ \\
\hline$C F$ & & $\begin{array}{c}0.136^{* * * *} \\
(10.17)\end{array}$ & $\begin{array}{c}0.109 * * * \\
(6.04)\end{array}$ \\
\hline$M V E$ & & $\begin{array}{c}1.538 * * * \\
(13.96)\end{array}$ & $\begin{array}{c}1.618 * * * \\
(14.69)\end{array}$ \\
\hline$Q \times E D G A R$ & & & $\begin{array}{c}-0.425 * * * \\
(-4.07)\end{array}$ \\
\hline$C F \times E D G A R$ & & & $\begin{array}{c}0.048 * * \\
(2.03)\end{array}$ \\
\hline$M V E \times E D G A R$ & & & $\begin{array}{c}-0.093 * * \\
(-2.16)\end{array}$ \\
\hline Firm FE & Yes & Yes & Yes \\
\hline Year-Quarter FE & Yes & Yes & Yes \\
\hline Observations & 66,628 & 66,628 & 66,628 \\
\hline Adjusted $R$-squared & 0.272 & 0.311 & 0.312 \\
\hline
\end{tabular}

Notes: This table reports the regression results on corporate investment with an alternative proxy for firm size i.e., the natural logarithm of market capitalization $(M V E)$. The dependent variable is the quarterly investment made by the firm (INVESTMENT), defined as capital expenditure in the next quarter scaled by the net property, plant, and equipment at the current quarter end. EDGAR is an indicator that equals one after a firm becomes a mandatory EDGAR filer, and zero otherwise. $Q$ is Tobin's Q. All other variables are defined in Appendix C. The $t$-statistics of robust standard errors clustered at the firm level are reported in parentheses. ***,**, and * indicate significance at the $1 \%, 5 \%$, and $10 \%$ levels, respectively. 
Table A2: Firm-Specific Investment-to-Price Sensitivity

\begin{tabular}{|c|c|c|c|}
\hline \multirow[t]{2}{*}{ Dependent Variable $=$} & \multicolumn{3}{|c|}{ INVESTMENT } \\
\hline & $(1)$ & $(2)$ & (3) \\
\hline EDGAR & $\begin{array}{c}0.785 * * * * \\
(4.83)\end{array}$ & $\begin{array}{c}0.543 * * * \\
(3.57)\end{array}$ & $\begin{array}{c}0.923 * * * * \\
(2.67)\end{array}$ \\
\hline$Q$ & & $\begin{array}{c}1.711 * * * \\
(18.95)\end{array}$ & $\begin{array}{c}1.490 * * * \\
(8.48)\end{array}$ \\
\hline$C F$ & & $\begin{array}{c}0.177 * * * * \\
(12.93)\end{array}$ & $\begin{array}{c}0.091 * * * \\
(4.69)\end{array}$ \\
\hline SIZE & & $\begin{array}{c}0.356^{* * *} \\
(2.12)\end{array}$ & $\begin{array}{c}0.468 * * \\
(2.23)\end{array}$ \\
\hline$Q \times E D G A R$ & & & $\begin{array}{c}-0.234 * * \\
(-1.99)\end{array}$ \\
\hline$C F \times E D G A R$ & & & $\begin{array}{c}0.069 * * * \\
(2.92)\end{array}$ \\
\hline$S I Z E \times E D G A R$ & & & $\begin{array}{l}-0.054 \\
(-1.02)\end{array}$ \\
\hline Firm FE & Yes & Yes & Yes \\
\hline Year-Quarter FE & Yes & Yes & Yes \\
\hline$Q \times$ Firm FE & Yes & Yes & Yes \\
\hline Observations & 66,628 & 66,628 & 66,628 \\
\hline Adjusted $R$-squared & 0.272 & 0.302 & 0.346 \\
\hline
\end{tabular}

Notes: This table reports the regression results after we augment Equation (2) by interacting $Q$ with firm fixed effects to allow the investment-to-price sensitivity to vary across firms. The dependent variable is the quarterly investment made by the firm (INVESTMENT), defined as capital expenditure in the next quarter scaled by the net property, plant, and equipment at the current quarter end. EDGAR is an indicator that equals one after a firm becomes a mandatory EDGAR filer, and zero otherwise. $Q$ is Tobin's Q. All other variables are defined in Appendix C. The $t$-statistics of robust standard errors clustered at the firm level are reported in parentheses. ***, $* *$, and $*$ indicate significance at the $1 \%, 5 \%$, and $10 \%$ levels, respectively. 
Table A3: Debt Financing

\begin{tabular}{lcc}
\hline \hline Dependent Variable & \multicolumn{2}{c}{ DEBT } \\
\cline { 2 - 3 } EDGAR & $(1)$ & $(2)$ \\
& & $\mathbf{- 0 . 1 1 1}$ \\
SIZE & $\mathbf{- 0 . 1 0 1}$ & $\mathbf{( - 1 . 4 6 )}$ \\
& $\mathbf{( - 1 . 3 4 )}$ & $-0.490^{* * *}$ \\
PRC_INV & & $(-6.05)$ \\
& & $-0.456^{* * *}$ \\
Firm FE & & $(-5.03)$ \\
Year-Quarter FE & & \\
Observations & Yes & Yes \\
Adjusted $R$-squared & Yes & Yes \\
\hline \hline
\end{tabular}

Notes: This table reports the regression results on debt financing. The dependent variable is the amount of debt issuance (DEBT). Following Shroff (2020), we define DEBT as net debt issuance (DLTISQ minus DLTRQ) scaled by lag total assets (ATQ); when DLTISQ and DLTRQ are missing, this variable equals the change in total debt for the company (change in DLTTQ plus change in DLCQ) scaled by lag total assets. EDGAR is an indicator that equals one after a firm becomes a mandatory EDGAR filer, and zero otherwise. All other variables are defined in Appendix C. The $t$-statistics of robust standard errors clustered at the firm level are reported in parentheses. $* * *, * *$, and $*$ indicate significance at the $1 \%, 5 \%$, and $10 \%$ levels, respectively. 
Table A4: Quasi-Indexers and Dedicated Institutional Investors

\begin{tabular}{|c|c|c|c|c|}
\hline \multirow[t]{2}{*}{ Dependent Variable $=$} & \multicolumn{2}{|c|}{ INSTOWN_QIX } & \multicolumn{2}{|c|}{ INSTOWN_DED } \\
\hline & (1) & (2) & (3) & (4) \\
\hline EDGAR & $\begin{array}{c}-0.816 * * * \\
(-4.92)\end{array}$ & $\begin{array}{c}-0.734 * * * * \\
(-4.51)\end{array}$ & $\begin{array}{c}0.417 * * \\
(2.35)\end{array}$ & $\begin{array}{c}0.467 * * * \\
(2.66)\end{array}$ \\
\hline SIZE & & $\begin{array}{c}3.183 * * * \\
(16.80)\end{array}$ & & $\begin{array}{c}1.804 * * * \\
(9.06)\end{array}$ \\
\hline PRC_INV & & $\begin{array}{c}-1.769 * * * \\
(-9.25)\end{array}$ & & $\begin{array}{c}-1.735 * * * \\
(-6.78)\end{array}$ \\
\hline Firm FE & Yes & Yes & Yes & Yes \\
\hline Year-Quarter FE & Yes & Yes & Yes & Yes \\
\hline Observations & 66,141 & 66,141 & 66,141 & 66,141 \\
\hline Adjusted $R$-squared & 0.819 & 0.827 & 0.670 & 0.676 \\
\hline
\end{tabular}

Notes: This table repeats the regression of Table 4 for the other two types of institutional investors: quasiindexers (who use indexing or buy-and-hold strategies characterized by high diversification and low portfolio turnover) and dedicated institutional investors (who have large, long-term holdings concentrated in only a few firms). The dependent variables include the percentage of shares held by quasi-indexers (INSTOWN_QIX) and the percentage of shares held by dedicated institutional investors (INSTOWN_DED). EDGAR is an indicator that equals one after a firm becomes a mandatory EDGAR filer, and zero otherwise. All other variables are defined in Appendix C. The $t$-statistics of robust standard errors clustered at the firm level are reported in parentheses. $* * *, * *$, and $*$ indicate significance at the $1 \%, 5 \%$, and $10 \%$ levels, respectively. 
Figure A1: Dynamic Test of ROE

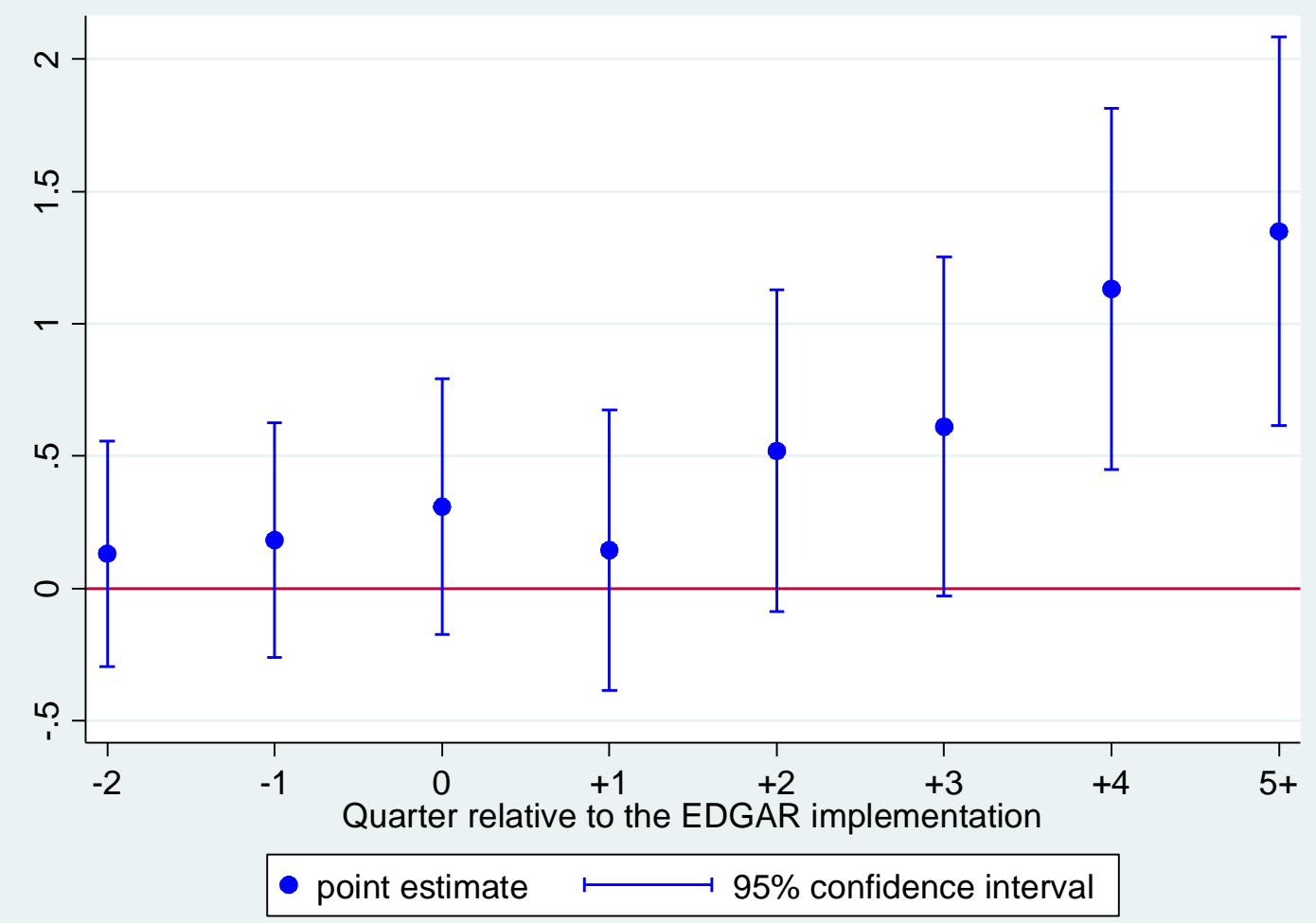

Notes: This figure reports the results from an event-time analysis of the effect of the EDGAR implementation on ROE. Specifically, we re-estimate the regression model on $R O E$ in column 1 of Table 6 by replacing EDGAR with a set of indicators for the quarters around the EDGAR implementation for each firm in our sample. Specifically, the regression model is as follows:

$$
\begin{aligned}
R O E_{i, t}=\alpha_{t}+\eta_{i} & +\gamma_{1} \operatorname{EDGAR}(-2)_{i, t}+\gamma_{2} \operatorname{EDGAR}(-1)_{i, t}+\gamma_{3} \operatorname{EDGAR}(0)_{i, t}+\gamma_{4} \operatorname{EDGAR}(+1)_{i, t} \\
& +\gamma_{5} \operatorname{EDGAR}(+2)_{i, t}+\gamma_{6} \operatorname{EDGAR}(+3)_{i, t}+\gamma_{7} \operatorname{EDGAR}(+4)_{i, t}+\gamma_{8} \operatorname{EDGAR}(5+)_{i, t}+\varepsilon_{i, t}
\end{aligned}
$$

where $\operatorname{EDGAR}(-2)_{i, t}\left(\operatorname{EDGAR}(-1)_{i, t}\right)$ is an indicator that equals one if a firm will become a mandatory EDGAR filer in two quarters (one quarter), and zero otherwise. $E D G A R(0)_{i, t}$ is an indicator that equals one if a firm becomes a mandatory EDGAR filer in the current quarter $t$, and zero otherwise. EDGAR $(+1)_{i, t}$ $\left(\operatorname{EDGAR}(+2)_{i, t}, \operatorname{EDGAR}(+3)_{i, t}, \operatorname{EDGAR}(+4)_{i, t}\right)$ is an indicator that equals one if a firm became a mandatory EDGAR filer one quarter (two quarters, three quarters, four quarters) ago, and zero otherwise. $E D G A R(5+)_{i, t}$ is an indicator that equals one if a firm became a mandatory EDGAR filer five or more quarters ago, and zero otherwise. The figure reports the coefficient estimates on each event quarter indicator as well as their 95\% confidence intervals. The estimation includes firm and year-quarter fixed effects. The standard errors are clustered at the firm level. 
Figure A2: Dynamic Test of $R O A$

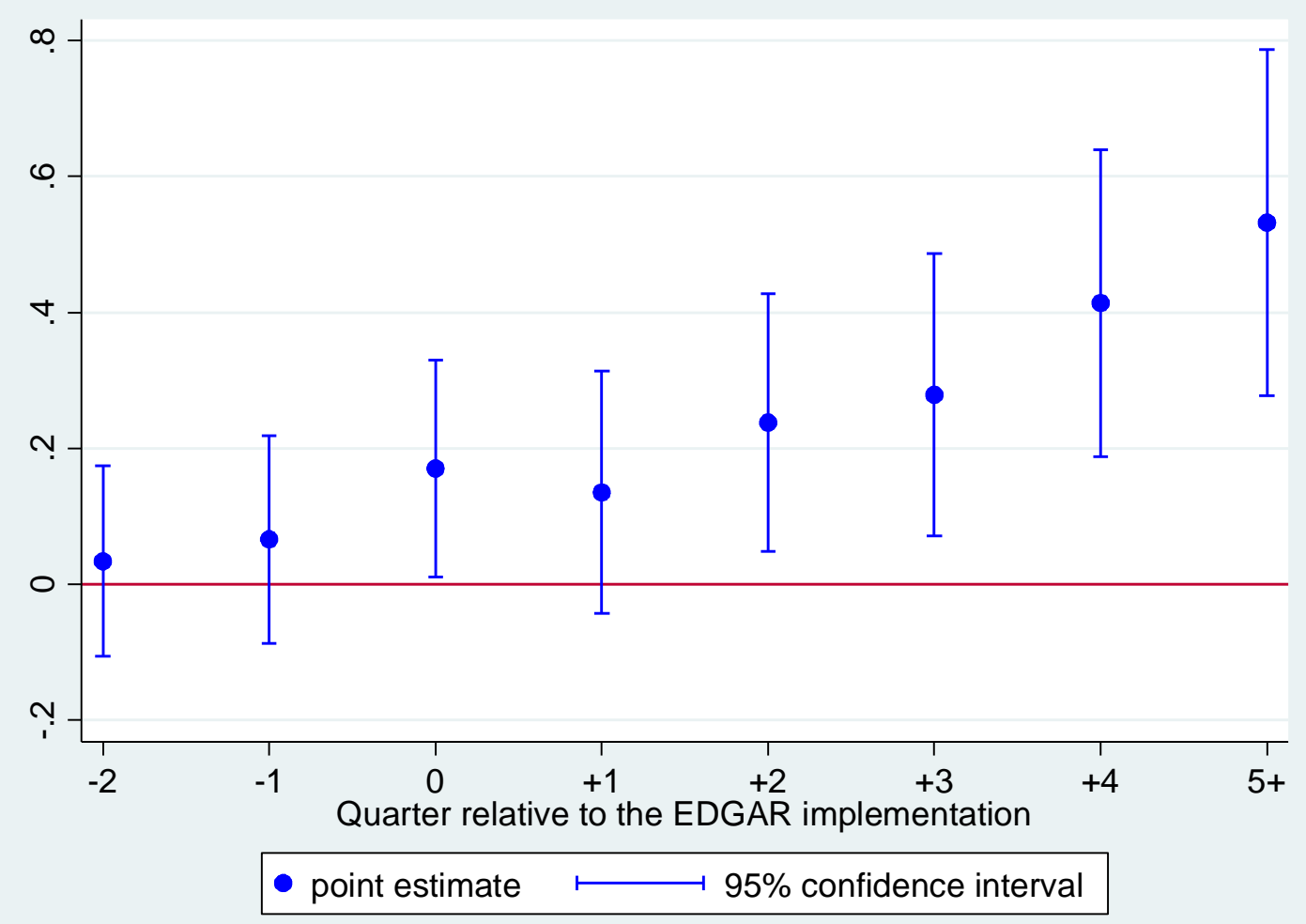

Notes: This figure reports the results from an event-time analysis of the effect of the EDGAR implementation on ROA. Specifically, we re-estimate the regression model on ROA in column 3 of Table 6 by replacing EDGAR with a set of indicators for the quarters around the EDGAR implementation for each firm in our sample. Specifically, the regression model is as follows:

$$
\begin{aligned}
R O A_{i, t}=\alpha_{t}+\eta_{i} & +\gamma_{1} \operatorname{EDGAR}(-2)_{i, t}+\gamma_{2} \operatorname{EDGAR}(-1)_{i, t}+\gamma_{3} \operatorname{EDGAR}(0)_{i, t}+\gamma_{4} \operatorname{EDGAR}(+1)_{i, t} \\
& +\gamma_{5} \operatorname{EDGAR}(+2)_{i, t}+\gamma_{6} \operatorname{EDGAR}(+3)_{i, t}+\gamma_{7} \operatorname{EDGAR}(+4)_{i, t}+\gamma_{8} \operatorname{EDGAR}(5+)_{i, t}+\varepsilon_{i, t}
\end{aligned}
$$

where $\operatorname{EDGAR}(-2)_{i, t}\left(\operatorname{EDGAR}(-1)_{i, t}\right)$ is an indicator that equals one if a firm will become a mandatory EDGAR filer in two quarters (one quarter), and zero otherwise. $\operatorname{EDGAR}(0)_{i, t}$ is an indicator that equals one if a firm becomes a mandatory EDGAR filer in the current quarter $t$, and zero otherwise. EDGAR $(+1)_{i, t}$ $\left(\operatorname{EDGAR}(+2)_{i, t}, \operatorname{EDGAR}(+3)_{i, t}, \operatorname{EDGAR}(+4)_{i, t}\right)$ is an indicator that equals one if a firm became a mandatory EDGAR filer one quarter (two quarters, three quarters, four quarters) ago, and zero otherwise. $E D G A R(5+)_{i, t}$ is an indicator that equals one if a firm became a mandatory EDGAR filer five or more quarters ago, and zero otherwise. The figure reports the coefficient estimates on each event quarter indicator as well as their $95 \%$ confidence intervals. The estimation includes firm and year-quarter fixed effects. The standard errors are clustered at the firm level. 
Figure A3: Dynamic Test of $\triangle S A L E S$

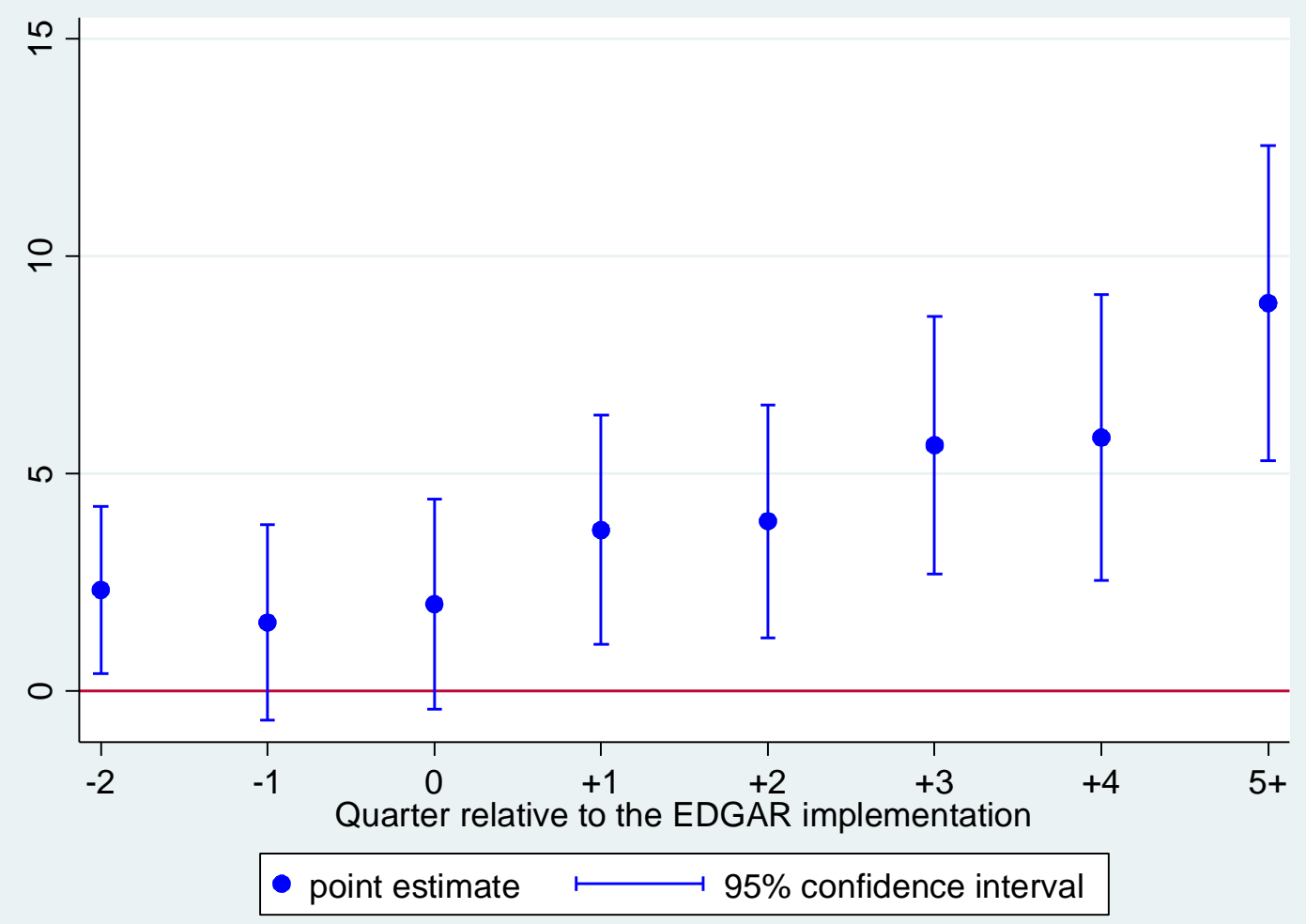

Notes: This figure reports the results from an event-time analysis of the effect of the EDGAR implementation on $\triangle S A L E S$. Specifically, we re-estimate the regression model on $\triangle S A L E S$ in column 5 of Table 6 by replacing $E D G A R$ with a set of indicators for the quarters around the EDGAR implementation for each firm in our sample. Specifically, the regression model is as follows:

$$
\begin{aligned}
\Delta \operatorname{SALES}_{i, t}=\alpha_{t} & +\eta_{i}+\gamma_{1} \operatorname{EDGAR}(-2)_{i, t}+\gamma_{2} \operatorname{EDGAR}(-1)_{i, t}+\gamma_{3} \operatorname{EDGAR}_{\left.(0)_{i, t}+\gamma_{4} \operatorname{EDGAR}_{(+1}\right)_{i, t}} \\
& +\gamma_{5} \operatorname{EDGAR}(+2)_{i, t}+\gamma_{6} \operatorname{EDGAR}(+3)_{i, t}+\gamma_{7} \operatorname{EDGAR}(+4)_{i, t}+\gamma_{8} \operatorname{EDGAR}(5+)_{i, t}+\varepsilon_{i, t}
\end{aligned}
$$

where $\operatorname{EDGAR}(-2)_{i, t}\left(\operatorname{EDGAR}(-1)_{i, t}\right)$ is an indicator that equals one if a firm will become a mandatory EDGAR filer in two quarters (one quarter), and zero otherwise. $\operatorname{EDGAR}(0)_{i, t}$ is an indicator that equals one if a firm becomes a mandatory EDGAR filer in the current quarter $t$, and zero otherwise. $E D G A R(+1)_{i, t}$ $\left(\operatorname{EDGAR}(+2)_{i, t}, \operatorname{EDGAR}(+3)_{i, t}, \operatorname{EDGAR}(+4)_{i, t}\right)$ is an indicator that equals one if a firm became a mandatory EDGAR filer one quarter (two quarters, three quarters, four quarters) ago, and zero otherwise. $E D G A R(5+)_{i, t}$ is an indicator that equals one if a firm became a mandatory EDGAR filer five or more quarters ago, and zero otherwise. The figure reports the coefficient estimates on each event quarter indicator as well as their 95\% confidence intervals. The estimation includes firm and year-quarter fixed effects. The standard errors are clustered at the firm level. 